\title{
Numerical prediction and experimental validation of impact sound radiation by timber joist floors
}

\author{
Pengchao Wang ${ }^{\mathrm{a}, *}$, Cédric Van hoorickx ${ }^{\mathrm{a}}$, Geert Lombaert $^{\mathrm{a}}$, Edwin Reynders $^{\mathrm{a}}$ \\ ${ }^{a}$ KU Leuven Faculty of Engineering Science, Department of Civil Engineering, Kasteelpark Arenberg 40, B-3001 \\ Leuven, Belgium
}

\begin{abstract}
Timber joist floors are widely applied in residential buildings. The accurate prediction of the sound radiated by timber joist floors is challenging due to the interaction between the impacting mass and the floor, orthotropy of the joist and plate components, the effects of the floor size and boundary conditions, etc. In the present work, state-of-the-art approaches for the prediction of impact forces, structural vibration, and radiated sound power were combined into a prediction method for the sound pressure level in a room due to sound radiation by an impacted timber joist floor. This method was then extensively validated in a case study. The natural frequencies and mode shapes of the decoupled joists and plates were both experimentally determined and computed from finite element models, and a good agreement was found when an orthotropic material model is considered for all components. A considerable variation in material properties between nominally identical parts was also discovered. The accuracy of the floor assembly model was subsequently investigated, also by means of modal testing. It was found that a correct representation of the boundary conditions plays a key role in the accuracy of the predicted floor vibration field. Finally, the radiated sound pressure levels were measured and computed. A satisfactory agreement between measurement and computation was observed. At very low frequencies, the interaction between the floor and room modes can play an important role, and a modal room model is employed instead.
\end{abstract}

Keywords: impact sound radiation, lightweight timber joist floor, model calibration, ISO tapping machine, finite element method, diffuse field model

\section{Introduction}

The market share of timber joist floors in residential buildings has steadily increased in recent years, since the prefabrication, transportation, and assembly of lightweight timber products are fast and relatively inexpensive $[1,2]$. Timber joist floors are considered sustainable, as wood is a renewable material, and construction of timber joist floors generates limited waste on site.

\footnotetext{
Postprint submitted to Applied Acoustics.

Published version: P. Wang, C. Van hoorickx, G. Lombaert, and E. Reynders. Numerical prediction and experimental validation of impact sound radiation by timber joist floors. Applied Acoustics, 162:107182, 2020. https://doi.org/10.1016/j.apacoust.2019.107182

${ }^{*}$ Corresponding author. Tel.: +32 (0) 16376284 .

Email address: pengchao.wang@kuleuven.be (Pengchao Wang)
} 
However, it is challenging to achieve good impact sound insulation with a bare timber joist floor, due to its low weight [3]. To improve the sound insulation of bare timber joist floors, components such as a floating screed or a suspended ceiling are added. This may result in acceptable impact sound insulation quality, as experimental studies have demonstrated [4]. Homb et al. [5, 6] collected experimental data of impact sound insulation for wooden joist floor configurations in European countries. They categorized timber joist configurations into different groups, and experimentally investigated the effects of various configurations on the impact sound insulation.

The efficient and cost-effective development and optimization of lightweight floor systems require a computationally efficient and sufficiently accurate mathematical prediction of their impact sound radiation, because the experimental testing of a large number of alternative configurations is expensive and time-consuming. However, such a prediction needs to address several challenges, including the predictions of (i) the impact force, (ii) the vibration field of the timber joist floor, and (iii) the sound power radiated by the floor into a room.

The first challenge lies in the prediction of the impact force that is exerted onto the floor. Even for the standardized ISO tapping machine [7], predicting the impact force with sufficient accuracy is challenging because - in contrast to heavy floors - the interaction between the actuator and the lightweight timber joist floor cannot usually be neglected. Heckl [8] and Ljunggren [9] provided solutions of infinite plate motion under rigid hammer excitation by solving the bending wave equations of plates. Timoshenko and Goodier [10], Petersson and Heckl [11], and Brunskog and Hammer [12] investigated the local action of a rigid hammer on an infinite plate, and derived expressions of local force mobility. Brunskog and Hammer [13] analyzed the interaction between an infinite lightweight floor and the ISO tapping machine using a lumped mass-spring-dashpot model. Rabold et al. [14] and Wittstock [15] investigated the impact forces of individual hammers of the ISO tapping machine, and focused on the time-dependent interaction between the tapping machine and floor. Despite the availability of fairly complex excitation models, the precise prediction of the ISO tapping machine impact force on a lightweight floor remains challenging. The impact force is for example determined by the hammer momentum change and the floor impedance [13, 15], which are generally difficult to quantify precisely.

The second challenge is predicting the vibration field of timber joist floors. Brunskog and Hammer [16], Chung and Emms [17], and Dickow et al. [18] provided analytical solutions for the vibration of lightweight periodic rib-stiffened plates, considering plate-joist coupling effects. Mayr and Gibbs $[19,20]$ computed the floor response due to structure-borne excitation, considering the mobilities of both the excitation source and the driving point. Since the amount of complexity that can be handled by analytical prediction models is limited, numerical approaches have also been presented. Negreira et al. [1] developed finite element (FE) models of timber T-junctions to investigate the influence of junction geometries on the vibro-acoustic performance. Kohrmann [2] constructed detailed FE models to extensively analyze vibration of various Cross-Laminated Timber (CLT) plates with lumber joists, hollow box girders, floating floors, and suspended ceilings. Paolini et al. [21] developed a high-order FE model of a CLT structure, and the unknown model parameters were determined by matching simulated and measured modal results in an iterative model calibration process. Bard et al. [22] proposed numerical simulations using different techniques. At low frequencies, the structural components, acoustic cavities, and poroelastic filling of timber joist floors are modeled using different types of FE meshes. At higher frequencies, the transfer matrix method is applied to model multi-layered structures, and statistical energy analysis (SEA) is used to model the floors. The predictive accuracy of the numerical models heavily depends 
also on the accuracy of the dynamic material properties of the floor components (they are often orthotropic and not specified by manufacturers and/or may be subject to considerable variability), and on whether the assumptions regarding the connections between the different components and the boundary conditions are realistic or not.

The third challenge, i.e., the prediction of the sound power that is radiated by the floor into the receiving room, requires the consideration of different frequency regimes. Neves e Sousa and Gibbs $[23,24]$ developed an analytical model to compute the acoustic response in the room under a point-loaded floor at low frequencies. They highlighted the effects of floor-room modal coupling on the acoustic response. Bard et al. [22] analyzed the pressure field in the receiving room using a basis of analytical solutions of the Helmholtz equation. At medium and high frequencies, most authors, including Hopkins [25], modeled the sound field in the room as diffuse. If the influence of the diffuse sound pressure field on the floor vibration field is negligible, the sound power that is radiated by the floor into the room can be approximated as the sound power that is radiated into the direct field only, i.e., into an acoustic halfspace. Nevertheless, for finite floors, this typically necessitates a numerical evaluation of the Rayleigh integral $[26,27]$. As a result, the modal behavior of the floor at medium and high frequencies is often neglected in impact sound insulation predictions [25], although for lightweight structures such as joist floors, it can have an important effect.

The aim of the present work is to investigate the degree of accuracy to which the impact sound insulation of timber joist floors can be predicted with currently available, computationally efficient state-of-the-art approaches for the prediction of impact forces, structural vibration, and radiated sound power. The first contribution of the present work consists of combining these approaches into a practical numerical impact sound insulation prediction method for joist floors. The second and main contribution of the present work lies in the systematic and detailed experimental validation of this numerical method by means of a detailed case study. The validation is performed at three levels: the component level, the floor assembly level, and the system level (impact source - floor - room). At the component level, it is investigated to what extent the vibration behavior of the individual joists and plywood plates can be well represented by the adopted finite element approach which includes an orthotropic material model of all components. In order to eliminate the uncertainty due to imprecise knowledge of the material stiffness parameter values as much as possible, they are systematically calibrated using the experimentally determined eigenmodes of the separate floor components. By performing such calibration for each component, the variability of the material properties of nominally identical components is also quantified. At the floor level, it is investigated, also by means of modal testing, to what degree of accuracy the vibration behavior of the floor assembly can be represented by the adopted component coupling model and assumed boundary conditions. Finally, at the system level, it is investigated to what extent the sound pressure level can be accurately predicted. It is emphasized that, although the focus of the present experimental validation is on the direct impact sound radiation by a bare timber joist floor, the prediction framework can be generalized to various complex timber joist floor configurations, as they can be numerically modeled in the same way.

The outline of the paper is as follows. Section 2 introduces the proposed numerical prediction method for impact sound radiation prediction of timber joist floors. Section 3 introduces the case study considered in this work, and the stiffness parameter calibration of the floor components. Section 4 describes the assembled FE model of the floor and its boundary conditions. Section 5 performs an experimental validation of the predicted sound pressure levels due to different types of excitation. Finally, section 6 concludes the work. 


\section{Numerical prediction method}

In this section, a numerical method for predicting the impact sound radiation by a lightweight timber joist floor is presented. It consists of two main steps. Section 2.1 introduces the first step, which is the computation of the impact force of the ISO tapping machine and the resulting floor vibration. In the second step, which is detailed in section 2.2 , the sound power radiated by the vibrating floor is computed.

\subsection{ISO tapping machine impact force}

In the present work, the ISO tapping machine impact force is predicted in accordance with the mass-impedance model proposed by Brunskog and Hammer for general floor systems [13, Sec. 4]. However, the five tapping machine hammers are modeled separately, and the global driving point impedance of the floor will be determined by a finite element model of the floor structure rather than by an analytical approach.

The ISO tapping machine consists of five identical cylindrical hammers with a mass of $m_{\mathrm{h}}=$ $0.50 \mathrm{~kg}$ and a radius of $r_{\mathrm{h}}=1.50 \mathrm{~cm}$, and the nominal distance between two neighboring hammers is $10 \mathrm{~cm}$. Each hammer impacts the floor surface after a free fall from a height of $h=4 \mathrm{~cm}$, gaining an initial velocity $v_{\mathrm{h}, 0}=\sqrt{2 g h}$, with $g$ the gravitational acceleration. The impact excitation of each hammer has a repetition period of $T_{\mathrm{h}}=0.5 \mathrm{~s}$, resulting a repetition frequency $f_{\mathrm{h}}=1 / T_{\mathrm{h}}=2 \mathrm{~Hz}$. Numbering the five hammers in line from 1 to 5, the five hammers impact the floor following the order $1-3-5-2-4$, and the time shift between consecutive hammer impacts is $0.1 \mathrm{~s}$. Figure 1 displays a mass-impedance model, which is proposed by Brunskog and Hammer [13, Sec. 4] to describe a single excitation of an ISO tapping machine hammer on a finite floor.

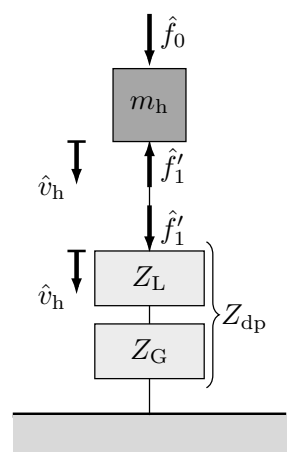

Figure 1: Mass-impedance model in the frequency domain for a single excitation of the ISO tapping machine hammer on a finite floor.

It is assumed that the single excitation begins at time $t=0$. The hammer is assumed to be statically attached to the floor, and an impulse force $f_{0}(t)$ is applied on the hammer in an infinitesimally short duration between $t=0_{-}$and $t=0_{+}$. The hammer velocity $v_{\mathrm{h}}$ is zero at $t=0_{-}$, and becomes $v_{\mathrm{h}, 0}$ at $t=0_{+}$. The force impulse can be expressed as $f_{0}(t)=F_{0} \delta(t)$, with $F_{0}$ the magnitude of the impulse. The Fourier transform of $f_{0}(t)$ reads:

$$
\hat{f}_{0}(\omega)=\mathcal{F}\left\{f_{0}(t) ; \omega\right\}=\mathcal{F}\left\{F_{0} \delta(t) ; \omega\right\}=F_{0},
$$

where $\mathcal{F}\{\cdot\}$ indicates the Fourier transform. Note that $\hat{f}_{0}(\omega)=F_{0}$ is frequency independent. $\hat{f}_{1}^{\prime}$ in figure 1 represents the continuous impact force spectrum for the single hammer excitation, 
and the driving point impedance $Z_{\mathrm{dp}}$ consists of a local part $Z_{\mathrm{L}}$ and a global part $Z_{\mathrm{G}}$. The global impedance $Z_{\mathrm{G}}$ for a finite floor is complex, with its real and imaginary part representing the energy dissipating part and stiffness part, respectively. The equation of motion for the hammer is given by:

$$
\hat{f}_{0}-\hat{f}_{1}^{\prime}(\omega)=\mathrm{i} \omega m_{\mathrm{h}} \hat{v}_{\mathrm{h}}(\omega),
$$

where $\hat{v}_{\mathrm{h}}(\omega)=\mathcal{F}\left\{v_{\mathrm{h}}(t) ; \omega\right\}$ is the velocity spectrum of the hammer. As the floor at the contact point has the same velocity as the hammer, the equation of motion at the contact point is written as:

$$
\hat{f}_{1}^{\prime}(\omega)=\hat{v}_{\mathrm{h}}(\omega) Z_{\mathrm{dp}}(\omega)=\hat{v}_{\mathrm{h}}(\omega) \frac{Z_{\mathrm{G}}(\omega) Z_{\mathrm{L}}(\omega)}{Z_{\mathrm{G}}(\omega)+Z_{\mathrm{L}}(\omega)}=\frac{\hat{v}_{\mathrm{h}}(\omega)}{Y_{\mathrm{dp}}(\omega)},
$$

where $Y_{\mathrm{dp}}=1 / Z_{\mathrm{dp}}=Y_{\mathrm{G}}+Y_{\mathrm{L}}$ and $Y_{\mathrm{G}}=1 / Z_{\mathrm{G}}$ are the total driving point mobility and the global mobility, respectively. For a timber joist floor, the global impedance on top of joists can be largely different from the one between joists. In this work, the global impedance $Z_{\mathrm{G}}$ is computed using the detailed FE model of the floor, an example of which will be presented in section 4 . The FE modeling stage results in a mass matrix $\mathbf{M} \in \mathbb{C}^{n_{\text {dof }} \times n_{\text {dof }}}$ and a stiffness matrix $\mathbf{K} \in \mathbb{C}^{n_{\text {dof }} \times n_{\text {dof }}}$ of the floor, with $n_{\text {dof }}$ the number of degrees of freedom (DOFs) of the floor. Adopting a structural damping model with loss factor $\eta_{\mathrm{s}}$, the force and displacement response vectors relate to each other via the dynamic stiffness matrix of the floor $\mathbf{D}(\omega) \in \mathbb{C}^{n_{\mathrm{dof}} \times n_{\mathrm{dof}} \text { : }}$

$$
\mathbf{D}(\omega) \hat{\mathbf{u}}(\omega)=\hat{\mathbf{f}}(\omega), \quad \text { where } \quad \mathbf{D}(\omega):=-\omega^{2} \mathbf{M}+\mathbf{K}\left(1+\mathrm{i} \eta_{\mathbf{s}}(\omega)\right)
$$

in which $\hat{\mathbf{f}}(\omega) \in \mathbb{C}^{n_{\mathrm{dof}} \times 1}$ is the force vector at angular frequency $\omega$. Since the tapping force of each hammer is modeled as a point force, $\hat{\mathbf{f}}(\omega)$ has only one nonzero element, which equals the tapping force at the excitation point. If the corresponding input degree of freedom number is denoted by $j$, the global driving point impedance equals

$$
Z_{\mathrm{G}}(\omega)=\frac{-\mathrm{i} D_{j j}(\omega)}{\omega} .
$$

If necessary, radiation damping can be accounted for, either by including it in $\eta_{\mathrm{s}}$, or by adding the direct field dynamic stiffness matrices of the acoustic halfspaces involved to the structural dynamic stiffness matrix. The computation of the direct field dynamic stiffness matrices is discussed in the next section. The local impedance $Z_{\mathrm{L}}$ can be analytically approximated using Timoshenko and Goodier's approach [10]:

$$
Z_{\mathrm{L}}=\frac{2 E r_{\mathrm{h}}}{\mathrm{i} \omega(1+\nu)(1-\nu)},
$$

where $E$ and $\nu$ are the Young's modulus and Poisson's ratio for isotropic floor materials. In the derivation of this expression, it has been assumed that (i) the deformation of the medium that is in contact with the hammer remains elastic also at the contact surface, (ii) the contact surface deformation can be accurately predicted with an elastic halfspace model, and (iii) the stress distribution along the hammer-floor contact surface is parabolic [26]. 
Inserting Eq. (3) into Eq. (2) gives:

$$
\begin{aligned}
\hat{v}_{\mathrm{h}}(\omega) & =\frac{\hat{f}_{0}}{\mathrm{i} \omega m_{\mathrm{h}}+Z_{\mathrm{dp}}(\omega)} \\
\hat{f}_{1}^{\prime}(\omega) & =\frac{\hat{f}_{0}}{1+\mathrm{i} \omega m_{\mathrm{h}} / Z_{\mathrm{dp}}(\omega)} .
\end{aligned}
$$

To compute the applied force spectrum $\hat{f}_{0}$, the hammer velocity time history is evaluated first, using the following inverse Fourier transform:

$$
v_{\mathrm{h}}(t)=\mathcal{F}^{-1}\{\hat{v}(\omega) ; t\}=\frac{1}{2 \pi} \int_{-\infty}^{\infty} \frac{\hat{f}_{0} \exp (\mathrm{i} \omega t) \mathrm{d} \omega}{\mathrm{i} \omega m_{\mathrm{h}}+Z_{\mathrm{dp}}(\omega)} .
$$

At $t=0$, the hammer velocity $v_{\mathrm{h}}(0)$ has a value halfway between $v_{\mathrm{h}}\left(0_{-}\right)=0$ and $v_{\mathrm{h}}\left(0_{+}\right)=v_{\mathrm{h}, 0}$, i.e., $v_{\mathrm{h}}(0)=v_{\mathrm{h}, 0} / 2[13$, eq. 21$]$. The following expression is obtained:

$$
v_{\mathrm{h}}(0)=\frac{\hat{f}_{0}}{2 \pi} \int_{-\infty}^{\infty} \frac{\mathrm{d} \omega}{\mathrm{i} \omega m_{\mathrm{h}}+Z_{\mathrm{dp}}(\omega)}=\hat{f}_{0} I_{0}=\frac{v_{\mathrm{h}, 0}}{2},
$$

where the integral $I_{0}$ can either be computed numerically or analytically [13, Sec. 4]. Next, the single hammer impact force spectrum $\hat{f}_{1}^{\prime}(\omega)$ is obtained using Eq. (8), and the corresponding time history can be obtained by means of the inverse Fourier transform $f_{1}^{\prime}(t)=\mathcal{F}^{-1}\left\{\hat{f}_{1}^{\prime}(\omega) ; t\right\}[13]$. The time corresponding to the first zero crossing of the force is considered as the cut-off time:

$$
t_{\text {cut }}=\min \left\{t \mid t>0, f_{1}^{\prime}(t)=0\right\} .
$$

For an actual hammer excitation, the hammer is captured by the tapping machine when $t>t_{\text {cut }}$. The time history of the actual single impact force becomes:

$$
f_{1}(t)=f_{1}^{\prime}(t)\left[H\left(t_{\text {cut }}-t\right)-H(-t)\right],
$$

in which $H(\cdot)$ is a Heaviside step function.

The actual single impact force for the different hammers is now considered, taking the time shift between the hammer impacts into account. Assuming the impact of the hammer $k$ starts at $t=t_{k}$, its single impact force is obtained using the general expression in Eq. (12):

$$
f_{1}^{(k)}\left(t-t_{k}\right)=f_{1}^{\prime(k)}\left(t-t_{k}\right)\left[H\left(t_{\mathrm{cut}}+t_{k}-t\right)-H\left(t_{k}-t\right)\right],
$$

where the impact force of the hammer $k$ is denoted by the superscript ' $(k)$ '. Considering $t_{1}=0$ results in $t_{2}=0.3 \mathrm{~s}, t_{3}=0.1 \mathrm{~s}, t_{4}=0.4 \mathrm{~s}$, and $t_{5}=0.2 \mathrm{~s}$. The force spectrum for the actual single hammer excitation is obtained by a Fourier transform:

$$
\hat{f}_{1}^{(k)}(\omega)=\mathcal{F}\left\{f_{1}^{(k)}\left(t-t_{k}\right) ; t\right\}=\int_{-\infty}^{\infty} f_{1}^{(k)}\left(t-t_{k}\right) \exp (-\mathrm{i} \omega t) \mathrm{d} t=\exp \left(-\mathrm{i} \omega t_{k}\right) \int_{-\infty}^{\infty} f_{1}^{(k)}(t) \exp (-\mathrm{i} \omega t) \mathrm{d} t .
$$

Finally, the Fourier series coefficients of the impact force of the hammer $k$ are given by:

$$
\hat{f}_{\mathrm{imp}, n}^{(k)}=\hat{f}_{1}^{(k)}\left(\omega_{n}\right) f_{\mathrm{h}}=\frac{\exp \left(-\mathrm{i} \omega_{n} t_{k}\right)}{T_{\mathrm{h}}} \int_{-\infty}^{\infty} f_{1}^{(k)}(t) \exp \left(-\mathrm{i} \omega_{n} t\right) \mathrm{d} t \quad \text { with } \quad \omega_{n}=2 \pi n f_{\mathrm{h}}, n \in \mathbb{Z} .
$$


In [13, Sec. 5], it is discussed how the time and frequency resolutions can be adopted for the Fourier transform and the inverse Fourier transform. In section 5.3, the choices of the time and frequency resolutions considering a timber joist floor are furthermore discussed.

Additionally, it is often helpful to have a continuous spectral approximation of the floor response corresponding to the excitation of each hammer. One possibility consists of the averaging the single-sided power spectral density (PSD) of the hammer $k$ impact force in the frequency band $\left[\omega_{n}-\omega_{\mathrm{h}} / 2, \omega_{n}+\omega_{\mathrm{h}} / 2\right]$, with $\omega_{\mathrm{h}}=2 \pi f_{\mathrm{h}}$ :

$$
\hat{S}_{f f, \mathrm{imp}}^{(k)}(\omega) \approx \frac{\left|\hat{f}_{\mathrm{imp}, n}^{(k)}\right|^{2}}{2 \omega_{\mathrm{h}}}, \quad \omega \in\left[\omega_{n}-\omega_{\mathrm{h}} / 2, \omega_{n}+\omega_{\mathrm{h}} / 2\right] .
$$

Since the cut-off time $t_{\text {cut }}$ is generally much less than the time shift of $0.1 \mathrm{~s}$ between consecutive hammer impacts, it is considered that the impacts between different hammers do not influence each other. Therefore, the five tapping machine hammers are modeled as incoherent point sources, and the overall displacement spectrum of the floor corresponding to the excitation of the tapping machine can then be approximated as:

$$
\begin{aligned}
\hat{\mathbf{S}}_{\mathrm{uu}}(\omega) & \approx \sum_{k=1}^{5} \hat{\mathbf{S}}_{\mathrm{uu}}^{(k)}(\omega) \approx \sum_{k=1}^{5} \mathbf{D}_{j(k)}(\omega) \hat{S}_{f f, \mathrm{imp}}^{(k)}(\omega) \mathbf{D}_{j(k)}^{\mathrm{H}}(\omega) \\
& =\sum_{k=1}^{5} \frac{\left|\hat{f}_{\mathrm{imp}, n}^{(k)}\right|^{2}}{2 \omega_{\mathrm{h}}} \mathbf{D}_{j(k)}(\omega) \mathbf{D}_{j(k)}^{\mathrm{H}}(\omega), \quad \omega \in\left[\omega_{n}-\omega_{\mathrm{h}} / 2, \omega_{n}+\omega_{\mathrm{h}} / 2\right],
\end{aligned}
$$

where $\mathbf{D}_{j(k)}$ denotes the $j(k)^{\text {th }}$ column of $\mathbf{D}$, with $j(k)$ the input degree of freedom number corresponding to the location of the hammer $k$. The notation $(\cdot)^{\mathrm{H}}$ denotes the Hermitian transpose, i.e., $\mathbf{D}^{\mathrm{H}}=\mathbf{D}^{* \mathrm{~T}}$.

\subsection{Impact sound radiation}

Once the vibration field of the floor is known, the spatially averaged sound pressure level in the room due to sound radiation by the floor can be computed. The sound waves that are being radiated by the floor travel into the room, were they are scattered by objects inside the room and at the room boundaries. This scattered sound field is modeled as diffuse. If the influence of the diffuse sound pressure field on the floor vibration field is negligible, the sound power that is radiated by the floor into the room can be approximated as the sound power that is radiated into the direct field only, i.e., into an acoustic halfspace. In steady-state conditions, the input power into the direct field equals the power that is being dissipated in the diffuse field. The resulting sound radiation model is depicted in figure 2 .

The sound power that is radiated by the baffled floor into the direct field is computed by integrating the sound intensity over the floor-room interface $S$ [29]:

$$
\hat{P}_{\text {rad }}=\frac{\omega}{2} \int_{S} \operatorname{Im}\left\{\hat{u}(\omega, \mathbf{x})^{*} \hat{p}(\omega, \mathbf{x})\right\} \mathrm{d} \mathbf{x},
$$

and the sound pressure $\hat{p}$ at an arbitrary coordinate $\mathbf{x}$ of the floor is computed by the Rayleigh integral:

$$
\hat{p}(\omega, \mathbf{x})=-\frac{\omega^{2} \rho_{0}}{2 \pi} \int_{S} \hat{u}\left(\omega, \mathbf{x}^{\prime}\right) \frac{\exp \left(-\mathrm{i} k_{\mathrm{a}} r\right)}{r} \mathrm{~d} \mathbf{x}^{\prime}
$$


where $k_{\mathrm{a}}=\omega / c$ is the acoustic wavenumber in air, $c$ is the sound speed in air, $\rho_{0}$ is the air density, and $r=\left|\mathbf{x}^{\prime}-\mathbf{x}\right|$. Inserting Eq. (19) to Eq. (18) gives:

$$
\hat{P}_{\text {rad }}=\frac{\omega}{2}\left(-\frac{\omega^{2} \rho_{0}}{2 \pi}\right) \int_{S} \int_{S} \hat{u}(\omega, \mathbf{x})^{*} \operatorname{Im}\left\{\frac{\exp \left(-\mathrm{i} k_{\mathrm{a}} r\right)}{r}\right\} \hat{u}\left(\omega, \mathbf{x}^{\prime}\right) \mathrm{d} \mathbf{x}^{\prime} \mathrm{d} \mathbf{x}
$$

As the floor displacement field is discretized by the FE method, Eq. (20) is then rewritten in discretized form:

$$
\hat{P}_{\mathrm{rad}}=\frac{\omega}{2} \operatorname{Im}\left\{\hat{\mathbf{u}}^{\mathrm{H}}(\omega) \mathbf{R}^{\mathrm{T}} \mathbf{D}_{\mathrm{dir}}(\omega) \mathbf{R} \hat{\mathbf{u}}(\omega)\right\}=\frac{\omega}{2} \sum_{r, s} \operatorname{Im}\left\{D_{\mathrm{dir}, r s}(\omega)\right\} \hat{S}_{\mathrm{uu}, \mathrm{intf}, r s}(\omega),
$$

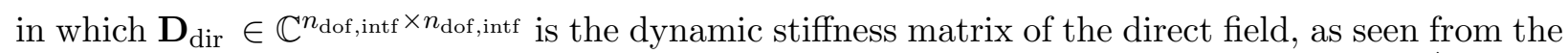
floor-room interface, with $n_{\text {dof,intf }}$ the number of DOFs along the floor-room interface. $\hat{S}_{\text {uu,intf }, r s}$

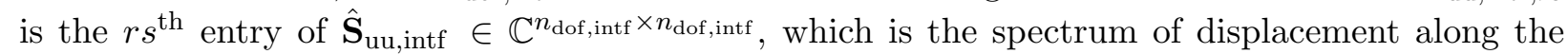
floor-room interface. $\mathbf{R} \in \mathbb{R}^{n_{\text {dof, intf }} \times n_{\text {dof }}}$ is the matrix that selects the displacement of the DOFs along the floor-room interface.

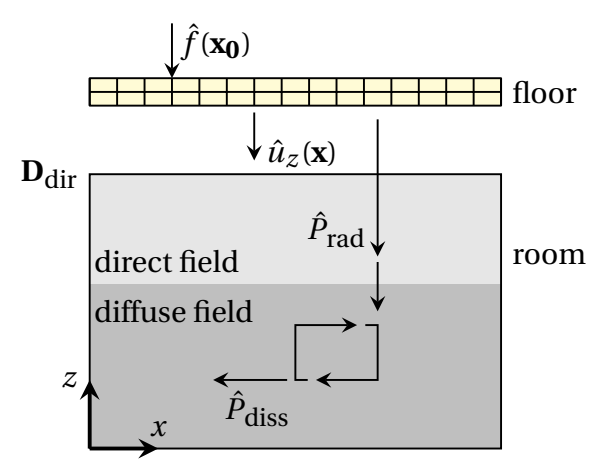

Figure 2: Model for sound radiation by a finite floor under impact excitation.

It can be computed by numerically evaluating the integral in Eq. (20) for any two combinations of FE displacement shape functions at the floor-room interface. However, it is often more computationally efficient to make a separate, coarser discretization of the floor displacement field at this interface. One possibility, which was adopted in the present paper, is to make use of wavelet shape functions for this discretization [30]. Practical implementation details related to this approach are summarized in [31, Sec. 2.3].

Next, the sound power flows in the room is analyzed to determine the impact sound pressure level in the room. Figure 2 illustrates that the radiated power $\hat{P}_{\text {rad }}$ is eventually dissipated in the diffuse field:

$$
\hat{P}_{\text {rad }}=\hat{P}_{\text {diss }},
$$

in which the dissipated power $\hat{P}_{\text {diss }}$ is computed as [32]:

$$
\hat{P}_{\text {diss }}=\omega \eta_{\mathrm{a}} \hat{E}_{\mathrm{a}}
$$

where $\hat{E}_{\mathrm{a}}$ is the mean total energy in the diffuse field, i.e., it is the total sound energy averaged over an ensemble of rooms with the same volume $V$ and acoustic damping loss factor $\eta_{\mathrm{a}}$, but with 
random wave scattering in the room and at its boundaries. The acoustic damping loss factor $\eta_{\mathrm{a}}$ is determined from the acoustic reverberation time $T_{\mathrm{a}}$ or the equivalent total absorption area $A$ [33]:

$$
\eta_{\mathrm{a}}=\frac{6 \ln (10)}{\omega T_{\mathrm{a}}}=\frac{c A}{4 \omega V}
$$

where $\ln$ denotes the natural logarithm. The ensemble mean of the sound energy $\hat{E}_{\mathrm{a}}$ is easily computed using Eqs. (21) to (23). The normalized impact sound pressure level in the receiving room equals:

$$
\hat{L}_{\mathrm{n}}=10 \log \frac{\hat{E}_{\mathrm{a}} \rho_{0} c^{2}}{V p_{0}^{2}}+10 \log \frac{A}{A_{0}},
$$

where $\log$ denotes the logarithm with base 10 , and $p_{0}=2 \times 10^{-5} \mathrm{~Pa}$ and $A_{0}=10 \mathrm{~m}^{2}$ are the reference sound pressure and the reference absorption area, respectively.

\section{Mechanical properties of floor components}

The numerical model presented in the previous section is experimentally validated in a case study considering a lightweight bare timber joist floor, as shown in figure 3, which is assembled in a $3 \mathrm{~m} \times 3 \mathrm{~m}$ opening in the KU Leuven Laboratory of Acoustics. The receiving room below the floor has a volume of $V=87 \mathrm{~m}^{3}$. The floor consists of two plywood plates supported by a total of seven joist beams. Each plate has nominal dimensions of $3 \mathrm{~m} \times 1.5 \mathrm{~m} \times 0.018 \mathrm{~m}$, and consists of seven thin timber layers. The fiber orientations of two adjacent thin layers are orthogonal. Each beam has nominal dimensions of $3 \mathrm{~m} \times 0.07 \mathrm{~m} \times 0.19 \mathrm{~m}$. Figure 4 shows the top, front, and side view of the floor, together with its dimensions, numbering of the separate components, and the Cartesian coordinate system. The $x$ - and $y$-axes are in the horizontal plane, and are perpendicular and parallel to the beams, respectively. As shown in the side view in figure 4, each beam end is trimmed in order to fit the support along the opening edges. Each beam is connected with the two plates by ten screws along the central longitudinal axis of the beam.

(a)

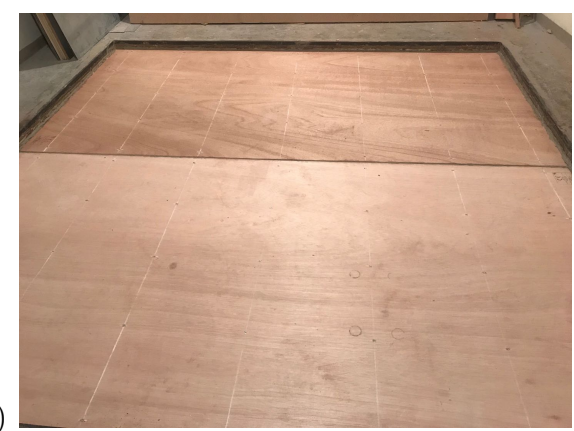

(b)

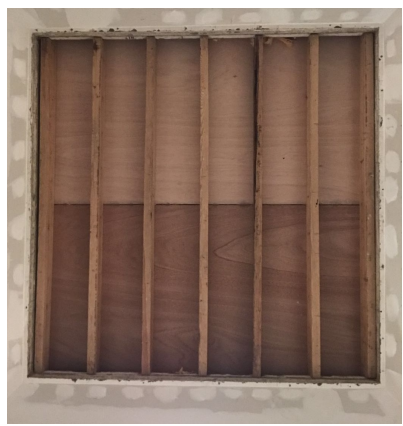

Figure 3: (a) Top and (b) bottom view of the considered lightweight timber joist floor assembled in a $3 \mathrm{~m} \times 3 \mathrm{~m}$ opening in the KU Leuven Laboratory of Acoustics.

Although the wooden texture is to some extent inhomogeneous, the floor components are assumed homogeneous in order to simplify the analysis. An orthotropic elastic material model is 
assumed for all floor components. In order to reduce the uncertainty related to the imprecise knowledge of the material parameters as much as possible, they were identified from experimental data as described in the following. The densities of the floor components were determined by weighing them separately. The results are listed in Table 1 . The stiffness parameters of the floor components, i.e., the Young's moduli, Poisson ratios, and shear moduli were experimentally calibrated. First, the mode shapes and natural frequencies of each floor component were experimentally identified by experimental modal analysis [34]. Next, the stiffness parameters were iteratively calibrated in a FE model calibration process [35]. The procedure of determining the beam and plate properties are described in sections 3.1 and 3.2 , respectively.

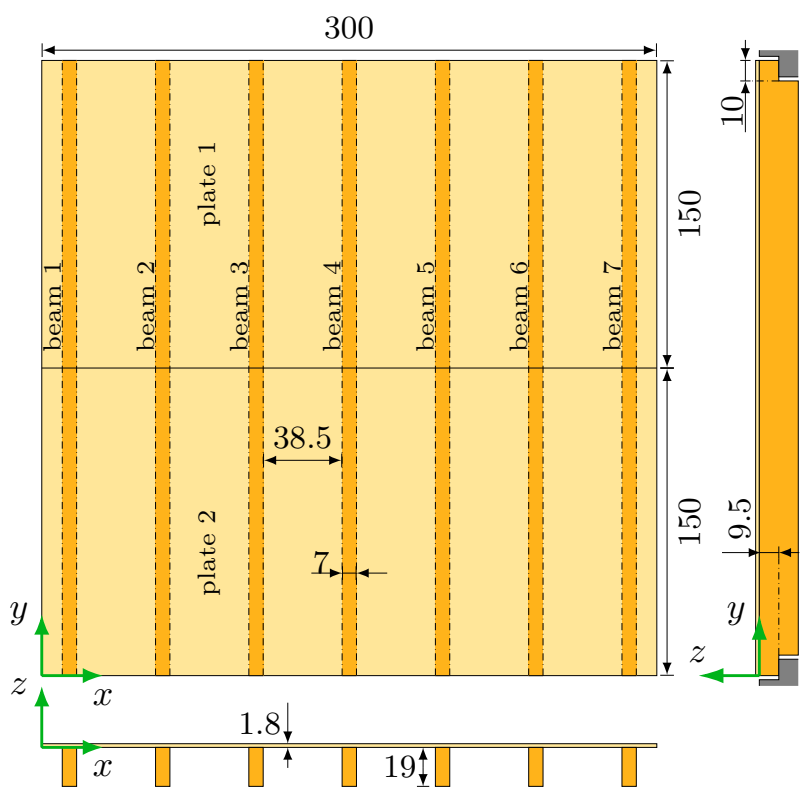

Figure 4: Top, front, and side view of the timber floor. The dimensions are in $[\mathrm{cm}]$.

\begin{tabular}{c|cc|ccccccc}
\hline Component & \multicolumn{2}{|c|}{ plate } & \multicolumn{7}{c}{ beam } \\
\hline No. & 1 & 2 & 1 & 2 & 3 & 4 & 5 & 6 & 7 \\
\hline Density $\rho\left[\mathrm{kg} / \mathrm{m}^{3}\right]$ & 515 & 535 & 489 & 511 & 593 & 561 & 484 & 524 & 534 \\
\hline
\end{tabular}

Table 1: Densities of the floor components.

\subsection{Beam properties}

A dynamic test was performed on each of the beams in order to identify its bending mode shapes and natural frequencies. Figure 5a displays the measurement setup, in which a beam was supported at its ends by tires to approximate dynamic free-free boundary conditions. Figure $5 \mathrm{~b}$ and $\mathrm{c}$ show the accelerometer setup on this beam. A local $x^{\prime} y^{\prime} z^{\prime}$-coordinate system was specified for the beams, in which the $x^{\prime}$ - and $y^{\prime}$ - axes are in the horizontal plane, and are parallel and perpendicular to the longitudinal axis of the beam. Seven PCB accelerometers with nominal sensitivities of 
$0.10 \mathrm{~V} /\left(\mathrm{m} / \mathrm{s}^{2}\right)$ and four Dytran accelerometers with nominal sensitivities of $0.01 \mathrm{~V} /\left(\mathrm{m} / \mathrm{s}^{2}\right)$ were attached on top of the beam along the central longitudinal axis, with a distance of $30 \mathrm{~cm}$ between two neighboring accelerometers. An impact hammer of the type PCB-086C03 was used to vertically impact the beam at the location of accelerometer 11, exciting the bending modes in the $x^{\prime} z^{\prime}$-plane. The force and acceleration signals during the excitation were acquired by a National Instruments (NI) PXI system, which consists of a PXI-1050 chassis with four PXI-4472B modules connected to a portable computer. A sampling frequency of $3000 \mathrm{~Hz}$ was used in this setup.

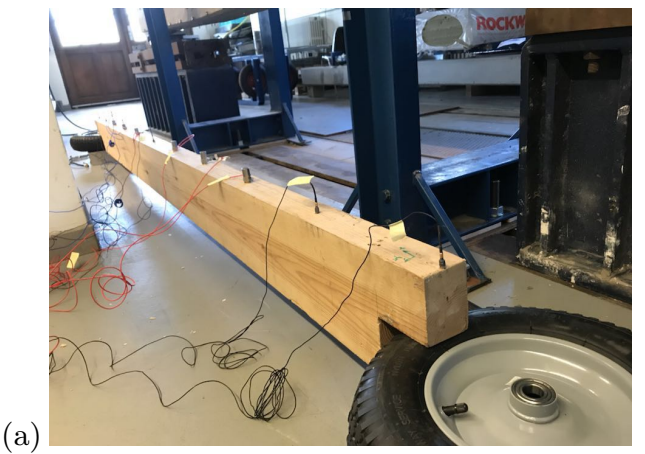

(b)

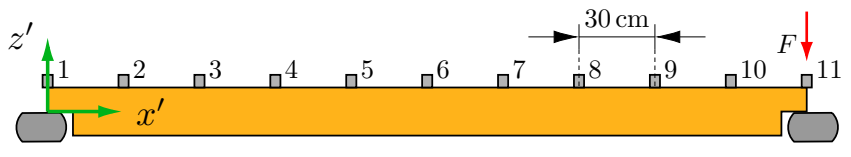

(c)

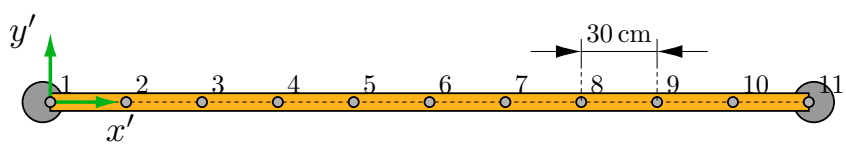

Figure 5: (a) Measurement setup of the dynamic test on one of the beams. The beam was supported at its ends by tires to approximate dynamic free-free boundary conditions. (b) Front and (c) top view of the accelerometer setup on one of the beams.

An acceleration-based modal analysis for each beam was performed using MACEC, a Matlab toolbox for experimental and operational modal analysis [36]. The Combined deterministicstochastic Subspace Identification (CSI) algorithm [37] was applied, in which both the input force and the output acceleration data were used for the identification. The model order was chosen in steps of two with a maximum order of 100, and the number of Hankel block rows $i$ was 80 . All the modes of the discrete-time state-space model for each setup were computed, and the first seven bending modes in the $x^{\prime} z^{\prime}$-plane were manually selected in the stabilization diagram for each test setup. Figure 6 displays the identified mode shapes $\phi_{\text {id }}$ and natural frequencies $f_{\text {id }}$, with the subscript 'id' indicating identified values. The scatter of these modal characteristics indicates the variability of the properties among the seven beams.

The mechanical properties of each beam were estimated by a model calibration process, in which the computed eigenmodes were compared against the identified eigenmodes of the beam. Figure 7 shows the FE model of one of the beams, which was constructed in ANSYS with 3D eight-node linear solid elements (of the SOLID45 type) of size $1.75 \mathrm{~cm} \times 2.0 \mathrm{~cm} \times 2.0 \mathrm{~cm}$. Free-free boundary conditions were used for the model. The orthotropic mechanical properties applied in the model are the Young's moduli $E_{\mathrm{x}^{\prime}}, E_{\mathrm{y}^{\prime}}$, and $E_{\mathrm{z}^{\prime}}$, the major Poisson's ratios $\nu_{\mathrm{x}^{\prime} \mathrm{y}^{\prime}}, \nu_{\mathrm{y}^{\prime} \mathrm{z}^{\prime}}$, and $\nu_{\mathrm{x}^{\prime} \mathrm{z}^{\prime}}$, and the shear moduli $G_{\mathrm{x}^{\prime} \mathrm{y}^{\prime}}, G_{\mathrm{y}^{\prime} \mathrm{z}^{\prime}}$, and $G_{\mathrm{x}^{\prime} \mathrm{z}^{\prime}}$. Since the fiber orientation coincides with the longitudinal axis of the beams, the properties of each beam were initially assumed transversely isotropic, implying that $E_{\mathrm{z}^{\prime}}=E_{\mathrm{y}^{\prime}}, \nu_{\mathrm{x}^{\prime} \mathrm{z}^{\prime}}=\nu_{\mathrm{x}^{\prime} \mathrm{y}^{\prime}}$, and $G_{\mathrm{x}^{\prime} \mathrm{z}^{\prime}}=G_{\mathrm{x}^{\prime} \mathrm{y}^{\prime}}$.

It was found that the parameters $E_{\mathrm{x}^{\prime}}$ and $E_{\mathrm{y}^{\prime}}=E_{\mathrm{z}^{\prime}}$ significantly influence the natural frequencies of the $x^{\prime} z^{\prime}$-plane bending modes, while the influence of the other parameters is negligible. For this reason, $E_{\mathrm{x}^{\prime}}$ and $E_{\mathrm{y}^{\prime}}$ were chosen as calibration parameters, while a realistic value of 0.30 was chosen for both $\nu_{\mathrm{x}^{\prime} \mathrm{y}^{\prime}}$ and $\nu_{\mathrm{y}^{\prime} \mathrm{z}^{\prime}}[38]$, and $G_{\mathrm{x}^{\prime} \mathrm{y}^{\prime}}, G_{\mathrm{x}^{\prime} \mathrm{z}^{\prime}}$, and $G_{\mathrm{y}^{\prime} \mathrm{z}^{\prime}}$ were estimated by the following 
formulas [39]:

$$
\begin{aligned}
& G_{\mathrm{x}^{\prime} \mathrm{y}^{\prime}}=\frac{\sqrt{E_{\mathrm{x}^{\prime}} E_{\mathrm{y}^{\prime}}}}{2\left(1+\sqrt{\nu_{\mathrm{x}^{\prime} \mathrm{y}^{\prime}} \nu_{\mathrm{y}^{\prime} \mathrm{x}^{\prime}}}\right)}=G_{\mathrm{x}^{\prime} \mathrm{z}^{\prime}} \\
& G_{\mathrm{y}^{\prime} \mathrm{z}^{\prime}}=\frac{\sqrt{E_{\mathrm{y}^{\prime}} E_{\mathrm{z}^{\prime}}}}{2\left(1+\sqrt{\nu_{\mathrm{y}^{\prime} \mathrm{z}^{\prime}} \nu_{\mathrm{z}^{\prime} \mathrm{y}^{\prime}}}\right)}=\frac{E_{\mathrm{y}^{\prime}}}{2\left(1+\nu_{\mathrm{y}^{\prime} \mathrm{z}^{\prime}}\right)},
\end{aligned}
$$

where the minor Poisson's ratios $\nu_{\mathrm{y}^{\prime} \mathrm{x}^{\prime}}$ and $\nu_{\mathrm{z}^{\prime} \mathrm{y}^{\prime}}$ are given by:

$$
\begin{aligned}
& \nu_{\mathrm{y}^{\prime} \mathrm{x}^{\prime}}=\nu_{\mathrm{x}^{\prime} \mathrm{y}^{\prime}} \frac{E_{\mathrm{y}^{\prime}}}{E_{\mathrm{x}^{\prime}}} \\
& \nu_{\mathrm{z}^{\prime} \mathrm{y}^{\prime}}=\nu_{\mathrm{y}^{\prime} \mathrm{z}^{\prime}} \frac{E_{\mathrm{z}^{\prime}}}{E_{\mathrm{y}^{\prime}}}=\nu_{\mathrm{y}^{\prime} \mathrm{z}^{\prime}} .
\end{aligned}
$$
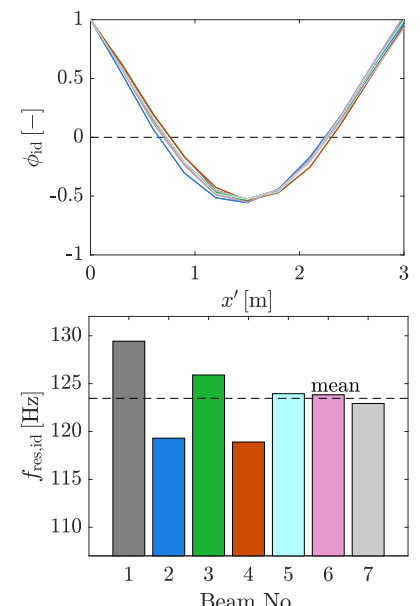

(a) mode 1
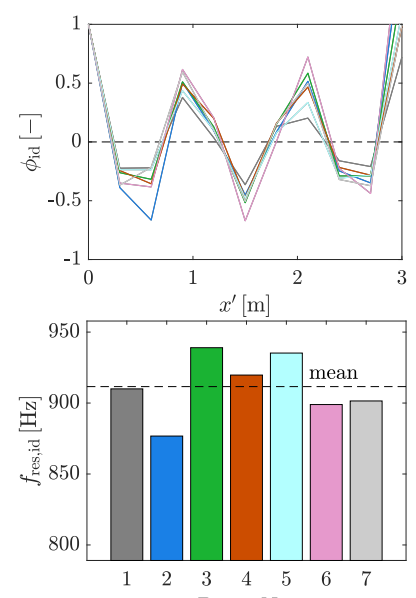

(e) mode 5
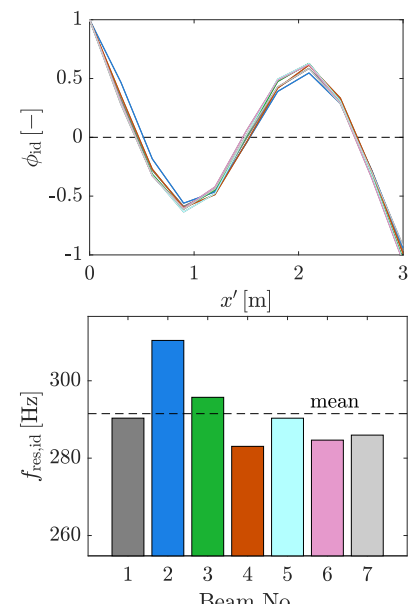

(b) mode 2
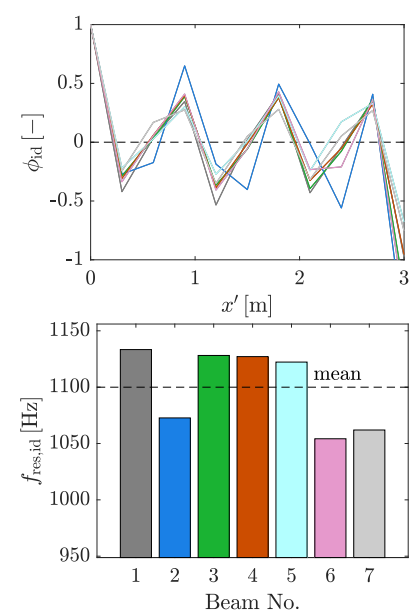

(f) mode 6
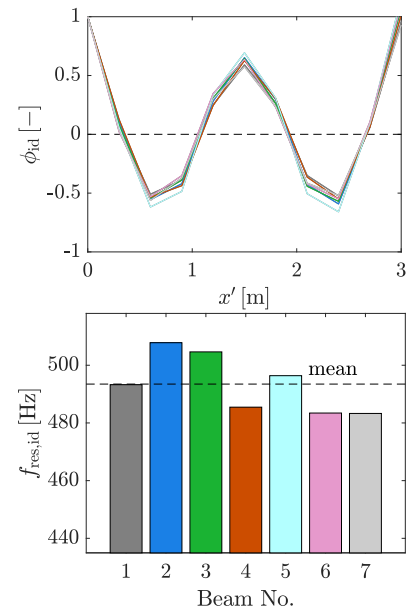

(c) mode 3
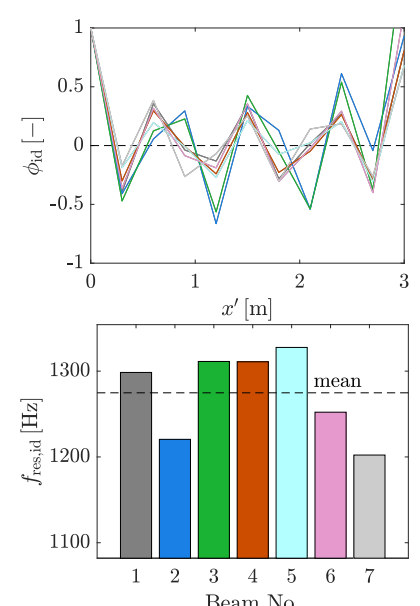

(g) mode 7
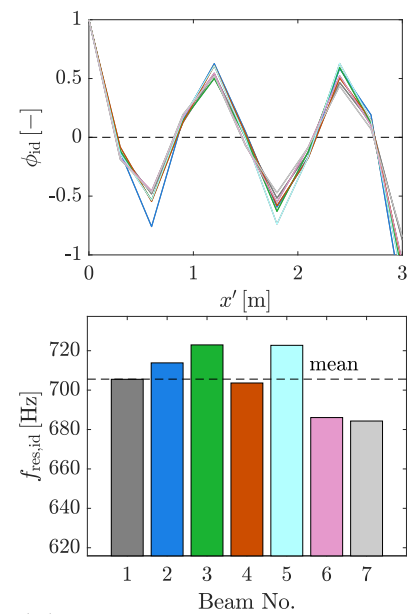

(d) mode 4

Figure 6: Identified mode shapes $\phi_{\mathrm{id}}$ and natural frequencies $f_{\mathrm{id}}$ of the first seven identified bending modes in the $x^{\prime} z^{\prime}$-plane for the seven beams. 


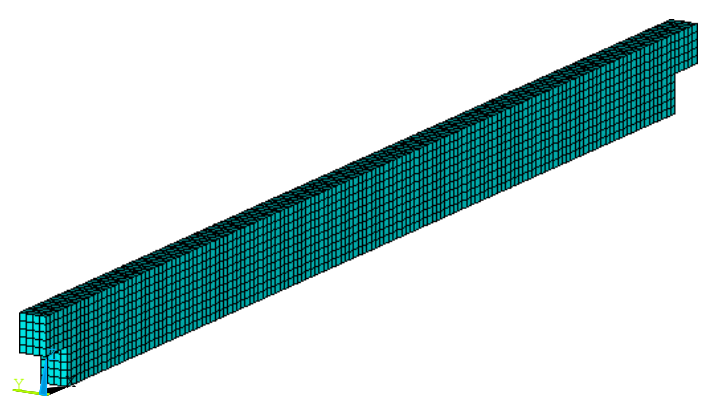

Figure 7: FE model of one of the beams. The model is constructed in ANSYS with 3D eight-node linear elements.

The material parameters $E_{\mathrm{x}^{\prime}}$ and $E_{\mathrm{y}^{\prime}}$ in each beam model were calibrated by minimizing the sum of squared distances $\mathrm{d}_{j}$ between each identified mode $j$ and the closest computed mode as a function of $E_{\mathrm{x}^{\prime}}$ and $E_{\mathrm{y}^{\prime}}$. The distance $\mathrm{d}_{j}$ is given by:

$$
\mathrm{d}_{j}\left(E_{\mathrm{x}^{\prime}}, E_{\mathrm{y}^{\prime}}\right)=\frac{\left|f_{\mathrm{id}, j}-f_{\mathrm{c}, j}\left(E_{\mathrm{x}^{\prime}}, E_{\mathrm{y}^{\prime}}\right)\right|}{\max \left(f_{\mathrm{id}, j}, f_{\mathrm{c}, j}\left(E_{\mathrm{x}^{\prime}}, E_{\mathrm{y}^{\prime}}\right)\right)}+1-\operatorname{MAC}\left(\phi_{\mathrm{id}, j}, \phi_{\mathrm{c}, j}\left(E_{\mathrm{x}^{\prime}}, E_{\mathrm{y}^{\prime}}\right)\right)
$$

in which the subscript ' $c$ ' indicates computed values. The modal assurance criterion (MAC) [40] measures the degree of correlation between identified and computed mode shapes:

$$
\operatorname{MAC}\left(\phi_{\mathrm{id}, j}, \phi_{\mathrm{c}, j}\left(E_{\mathrm{x}^{\prime}}, E_{\mathrm{y}^{\prime}}\right)\right)=\frac{\left|\phi_{\mathrm{id}, j}^{\mathrm{T}} \phi_{\mathrm{c}, j}\left(E_{\mathrm{x}^{\prime}}, E_{\mathrm{y}^{\prime}}\right)\right|^{2}}{\left\|\phi_{\mathrm{id}, j}\right\|^{2}\left\|\phi_{\mathrm{c}, j}\left(E_{\mathrm{x}^{\prime}}, E_{\mathrm{y}^{\prime}}\right)\right\|^{2}} .
$$

The MAC value is a positive real quantity that takes a value between zero and unity. A value close to unity indicates perfectly identical mode shapes, while a significantly lower value indicates mode shapes that are not strongly correlated. The objective function is defined as the sum of squared distances for modes 1 to 7 :

$$
f_{\mathrm{obj}}\left(E_{\mathrm{x}^{\prime}}, E_{\mathrm{y}^{\prime}}\right)=\sum_{j=1}^{7} \mathrm{~d}_{j}^{2}\left(E_{\mathrm{x}^{\prime}}, E_{\mathrm{y}^{\prime}}\right) .
$$

The minimization of $f_{\mathrm{obj}}\left(E_{\mathrm{x}^{\prime}}, E_{\mathrm{y}^{\prime}}\right)$ is a nonlinear least-squares problem that was numerically solved by an iterative, trust-region-reflective Newton method as implemented in the Matlab function lsqnonlin [35]. The absolute tolerances were set to $10^{-5}$ for the calibration parameters and the objective function. In each iteration, the mode shapes and natural frequencies were computed by the FE model, using the current values of parameters $E_{\mathrm{x}^{\prime}}$ and $E_{\mathrm{y}^{\prime}}$. During the calibration, the values of these two parameters were taken from realistic ranges of $1 \mathrm{GPa} \leq E_{\mathrm{x}^{\prime}} \leq 20 \mathrm{GPa}$ and $0.1 \mathrm{GPa} \leq E_{\mathrm{y}^{\prime}} \leq 3 \mathrm{GPa}$. Table 2 lists the optimized results of $E_{\mathrm{x}^{\prime}}, E_{\mathrm{y}^{\prime}}$, and $f_{\mathrm{obj}}\left(E_{\mathrm{x}^{\prime}}, E_{\mathrm{y}^{\prime}}\right)$ for the seven beams, and figure 8 shows the relative differences of mode shapes (measured as one minus the MAC value) and natural frequencies for the seven beams. In most cases, the MAC values are above 0.9 , and the relative natural frequency differences are below $5 \%$. The calibration results of beam 2 are however less satisfactory, implying certain structural imperfections or irregularities in beam 2 . 


\begin{tabular}{c|ccccccc}
\hline beam No. & 1 & 2 & 3 & 4 & 5 & 6 & 7 \\
\hline$E_{\mathrm{x}^{\prime}}[\mathrm{GPa}]$ & 13.99 & 13.42 & 16.28 & 15.33 & 14.02 & 15.06 & 14.84 \\
$E_{\mathrm{y}^{\prime}}[\mathrm{GPa}]$ & 0.21 & 0.19 & 0.28 & 0.25 & 0.21 & 0.18 & 0.17 \\
$f_{\mathrm{obj}}\left(E_{\mathrm{x}^{\prime}}, E_{\mathrm{y}^{\prime}}\right)[-]$ & 0.017 & 0.153 & 0.032 & 0.003 & 0.012 & 0.016 & 0.020 \\
\hline
\end{tabular}

Table 2: Optimized values of $E_{\mathrm{x}^{\prime}}, E_{\mathrm{y}^{\prime}}$ and $f_{\mathrm{obj}}\left(E_{\mathrm{x}^{\prime}}, E_{\mathrm{y}^{\prime}}\right)$ for the seven beams.
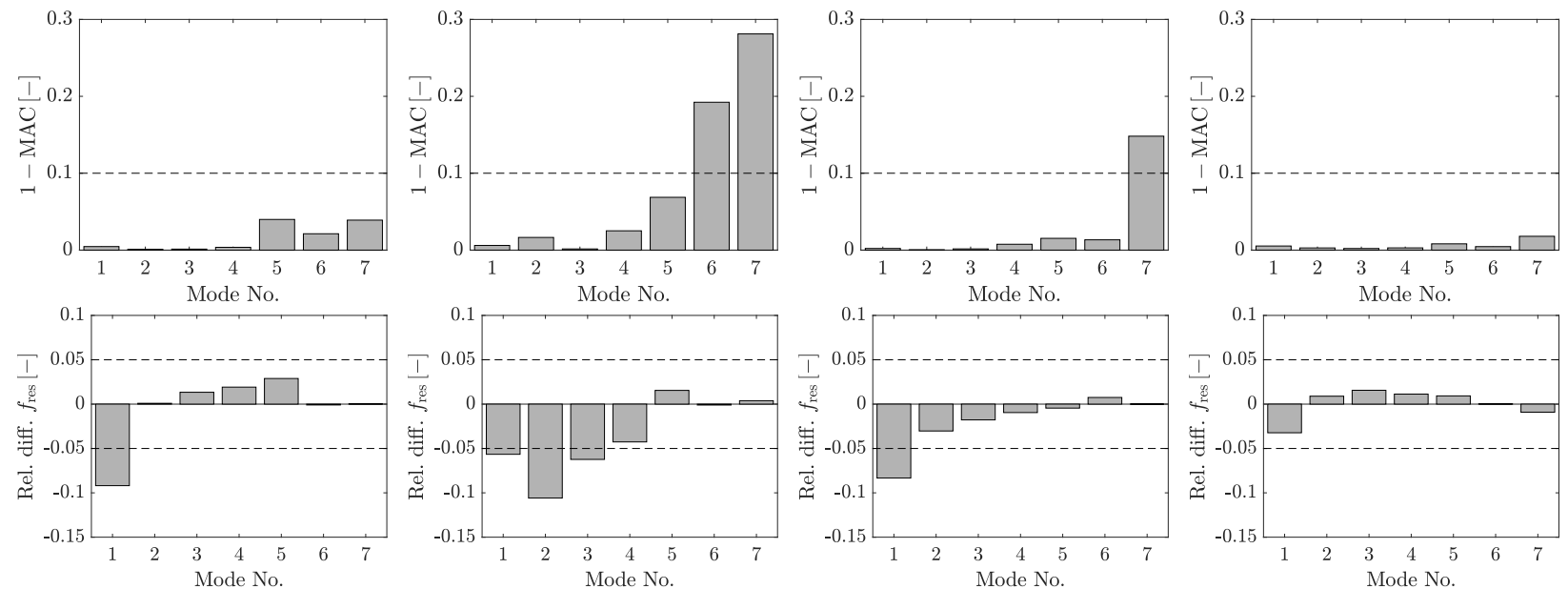

(a) beam 1

(b) beam 2

(c) beam 3

(d) beam 4
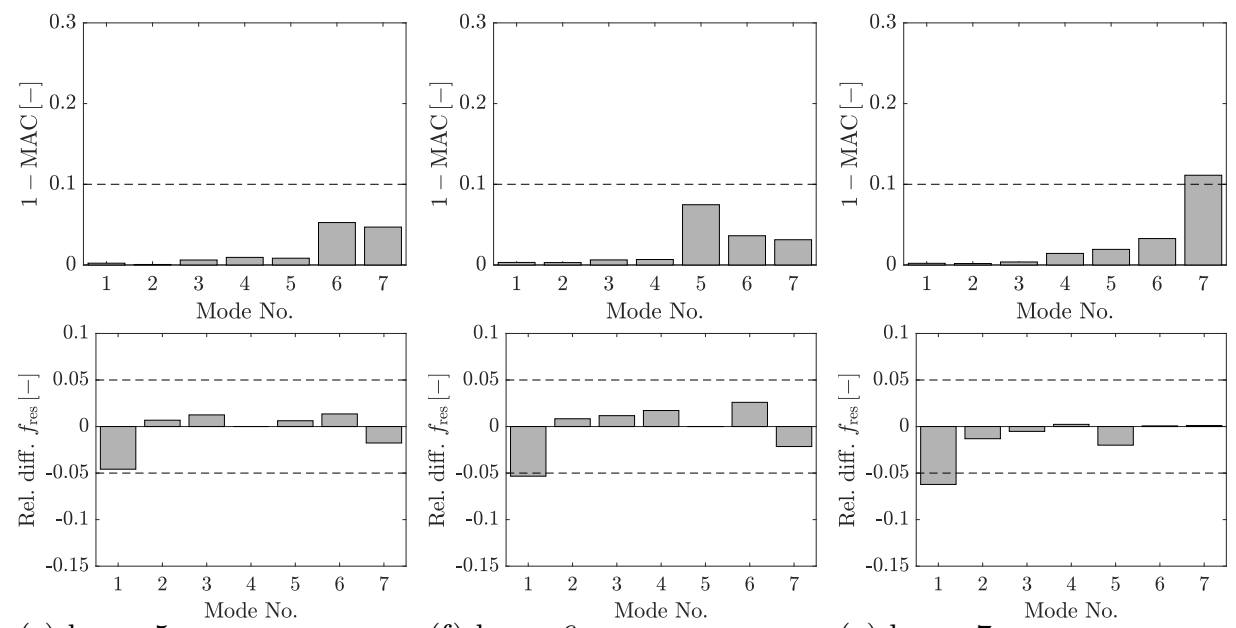

(e) beam 5

(f) beam 6

(g) beam 7

Figure 8: Relative differences of mode shapes (measured as 1-MAC) and natural frequencies between identified and computed modes for the seven beams.

\subsection{Plate properties}

A dynamic test was performed for each of the plates to identify its free bending mode shapes and natural frequencies. Figure 9 shows the measurement setup, in which a plate was freely suspended by ropes to approximate dynamic free-free boundary conditions. The test was performed in two setups. In each setup, $17 \mathrm{PCB}$ accelerometers with nominal sensitivities of $0.10 \mathrm{~V} /\left(\mathrm{m} / \mathrm{s}^{2}\right)$ and four 
Dytran accelerometers with nominal sensitivities of $0.01 \mathrm{~V} /\left(\mathrm{m} / \mathrm{s}^{2}\right)$ were attached to the plate. A hammer of the type PCB 086C03 was used to impact a plate corner, exciting the out-of-plane bending modes. The force and acceleration signals were acquired by the same NI PXI system described in section 3.1, and a sampling frequency of $1000 \mathrm{~Hz}$ was used.

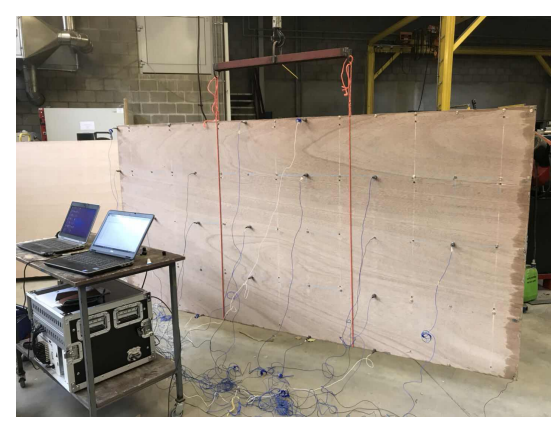

Figure 9: Measurement setup of the dynamic test on one of the plates. The plate was freely suspended by ropes to approximate dynamic free-free boundary conditions.

An acceleration-based modal analysis for each accelerometer setup was performed using MACEC, following the same processing procedure as in section 3.1, with the exception that the data were low-pass filtered with a cut-off frequency of $160 \mathrm{~Hz}$ and subsequently resampled at $200 \mathrm{~Hz}$, in order to focus on the range below $100 \mathrm{~Hz}$ in the modal analysis. The common modes selected from the two accelerometer setups were combined into a set of global modal characteristics. Figure 10 shows the mode shapes and natural frequencies of 12 identified out-of-plane bending modes of the two plates.

The process of calibrating the mechanical properties of the plates is similar to the one of the beams in section 3.1. Figure 11 illustrates the FE model of one of the plates, which was constructed in ANSYS with four-node linear thin shell elements (of the SHELL181 type) of size $2.5 \mathrm{~cm} \times 2.5 \mathrm{~cm}$. Free-free boundary conditions were used for the model. $E_{\mathrm{x}}, E_{\mathrm{y}}, \nu_{\mathrm{xy}}$, and $G_{\mathrm{xy}}$ were chosen as calibration parameters, as they have the largest influence on the computed eigenmodes. $E_{z}$ was estimated as $0.2 \mathrm{GPa}, \nu_{\mathrm{yz}}$ and $\nu_{\mathrm{xz}}$ were estimated as 0.33 [38], and $G_{\mathrm{yz}}$ and $G_{\mathrm{xz}}$ were computed as:

$$
\begin{aligned}
G_{\mathrm{yz}} & =\frac{\sqrt{E_{\mathrm{y}} E_{\mathrm{z}}}}{2\left(1+\sqrt{\nu_{\mathrm{yz}} \nu_{\mathrm{zy}}}\right)} \\
G_{\mathrm{xz}} & =\frac{\sqrt{E_{\mathrm{x}} E_{\mathrm{z}}}}{2\left(1+\sqrt{\nu_{\mathrm{xz}} \nu_{\mathrm{zx}}}\right)},
\end{aligned}
$$

in which the minor Poisson's ratios $\nu_{\mathrm{zy}}$ and $\nu_{\mathrm{zx}}$ are given by:

$$
\begin{aligned}
& \nu_{\mathrm{zy}}=\nu_{\mathrm{yz}} \frac{E_{\mathrm{z}}}{E_{\mathrm{y}}} \\
& \nu_{\mathrm{zx}}=\nu_{\mathrm{xz}} \frac{E_{\mathrm{z}}}{E_{\mathrm{x}}} .
\end{aligned}
$$




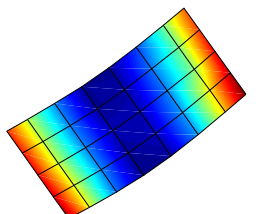

$6.58 \mathrm{~Hz}$

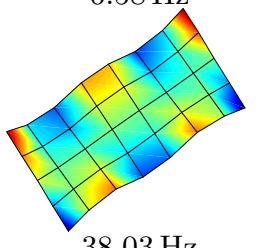

$38.03 \mathrm{~Hz}$

(a) plate 1

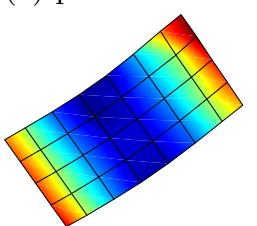

$6.17 \mathrm{~Hz}$

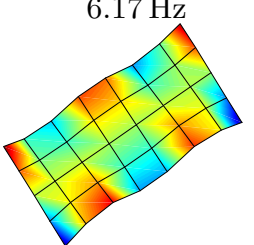

$36.46 \mathrm{~Hz}$

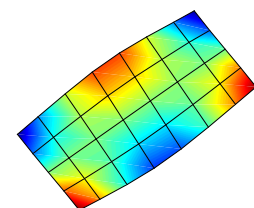

$9.86 \mathrm{~Hz}$

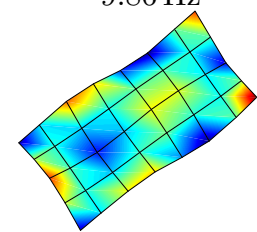

$39.53 \mathrm{~Hz}$
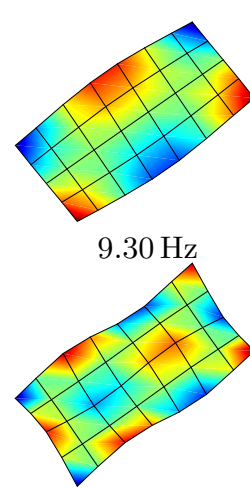

$39.81 \mathrm{~Hz}$

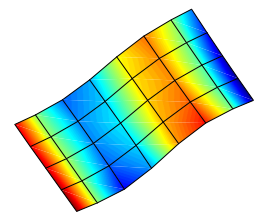

$18.08 \mathrm{~Hz}$

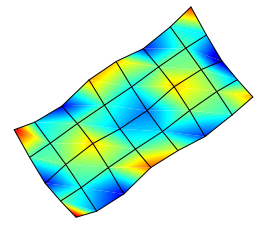

$53.57 \mathrm{~Hz}$
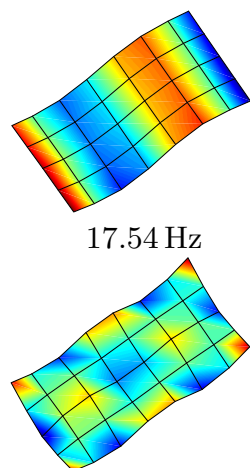

$52.75 \mathrm{~Hz}$

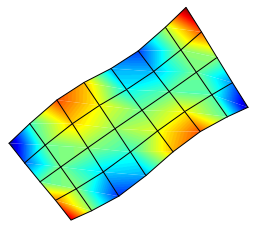

$20.94 \mathrm{~Hz}$

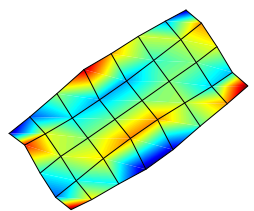

$73.04 \mathrm{~Hz}$

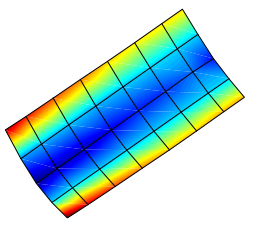

$25.32 \mathrm{~Hz}$

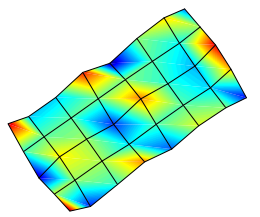

$75.10 \mathrm{~Hz}$

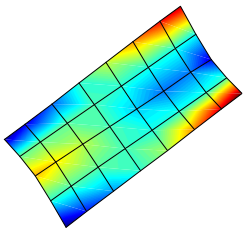

$26.30 \mathrm{~Hz}$

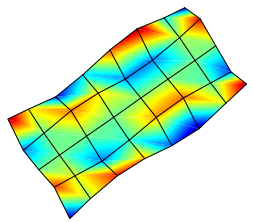

$79.20 \mathrm{~Hz}$

(b) plate 2

Figure 10: Mode shapes and natural frequencies of 12 identified out-of-plane bending modes of the two plates.

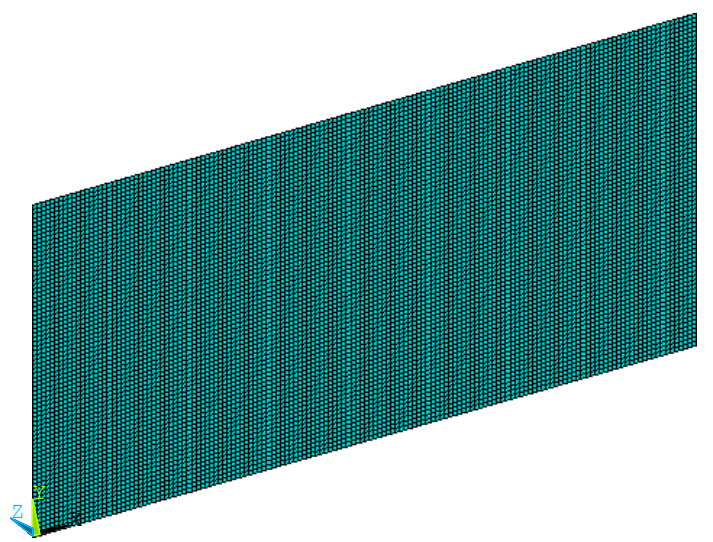

Figure 11: FE model of one of the plates. The model is constructed in ANSYS by four-node linear thin shell element.

$E_{\mathrm{x}}, E_{\mathrm{y}}, \nu_{\mathrm{xy}}$, and $G_{\mathrm{xy}}$ were simultaneously optimized by applying the iterative process of model 
calibration as described in section 3.1. The distance and objective function for this process are

$$
\begin{aligned}
\mathrm{d}_{j}\left(E_{\mathrm{x}}, E_{\mathrm{y}}, \nu_{\mathrm{xy}}, G_{\mathrm{xy}}\right)= & \frac{\left|f_{\mathrm{id}, j}-f_{\mathrm{c}, j}\left(E_{\mathrm{x}}, E_{\mathrm{y}}, \nu_{\mathrm{xy}}, G_{\mathrm{xy}}\right)\right|}{\max \left(f_{\mathrm{id}, j}, f_{\mathrm{c}, j}\left(E_{\mathrm{x}}, E_{\mathrm{y}}, \nu_{\mathrm{xy}}, G_{\mathrm{xy}}\right)\right)}+1 \\
& -\operatorname{MAC}\left(\phi_{\mathrm{id}, j}, \phi_{\mathrm{c}, j}\left(E_{\mathrm{x}}, E_{\mathrm{y}}, \nu_{\mathrm{xy}}, G_{\mathrm{xy}}\right)\right) \\
f_{\text {obj }}\left(E_{\mathrm{x}}, E_{\mathrm{y}}, \nu_{\mathrm{xy}}, G_{\mathrm{xy}}\right)= & \sum_{j=1}^{12} \mathrm{~d}_{j}^{2}\left(E_{\mathrm{x}}, E_{\mathrm{y}}, \nu_{\mathrm{xy}}, G_{\mathrm{xy}}\right) .
\end{aligned}
$$

The absolute tolerances were set to $10^{-5}$ for the calibration parameters and the objective function. The values of the four calibration parameters were taken from the following ranges during each iteration: $0.1 \mathrm{GPa} \leq E_{\mathrm{x}} \leq 20 \mathrm{GPa}, 0.1 \mathrm{GPa} \leq E_{\mathrm{y}} \leq 20 \mathrm{GPa}, 0.30 \leq \nu_{\mathrm{xy}} \leq 0.45$, and $0.1 \mathrm{GPa} \leq G_{\mathrm{xy}} \leq 10 \mathrm{GPa}$. Table 3 lists the optimized results for the two plates, and figures 12 shows the relative differences of mode shapes (measured as one minus the MAC value) and natural frequencies of each plate. As a good correspondence between the computed and identified modes is achieved, these calibrated parameters are applied in the remainder of the work.

\begin{tabular}{c|ccccc}
\hline plate No. & $E_{\mathrm{x}}[\mathrm{GPa}]$ & $E_{\mathrm{y}}[\mathrm{GPa}]$ & $\nu_{\mathrm{xy}}[-]$ & $G_{\mathrm{xy}}[\mathrm{GPa}]$ & $f_{\mathrm{obj}}\left(E_{\mathrm{x}}, E_{\mathrm{y}}, \nu_{\mathrm{xy}}, G_{\mathrm{xy}}\right)[-]$ \\
\hline 1 & 5.24 & 4.53 & 0.30 & 0.31 & 0.076 \\
2 & 4.96 & 5.06 & 0.33 & 0.31 & 0.072 \\
\hline
\end{tabular}

Table 3: Optimized values of $E_{\mathrm{x}}, E_{\mathrm{y}}, \nu_{\mathrm{xy}}$, and $G_{\mathrm{xy}}$ and $f_{\mathrm{obj}}\left(E_{\mathrm{x}}, E_{\mathrm{y}}, \nu_{\mathrm{xy}}\right)$ for the two plates.
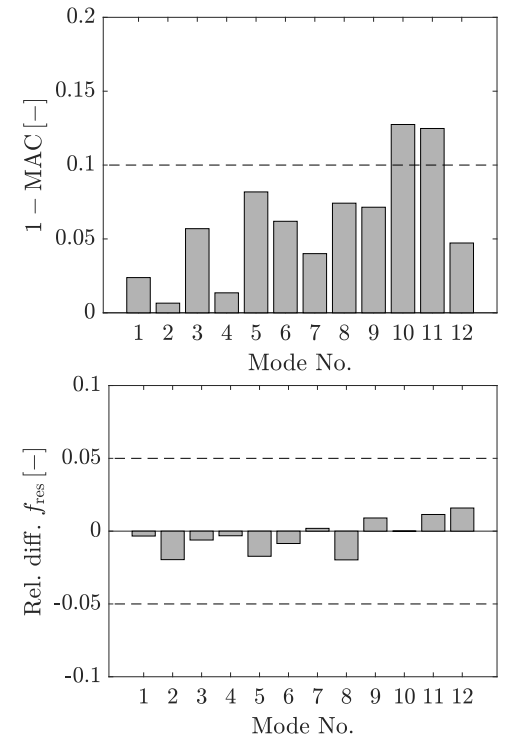

(a) plate 1
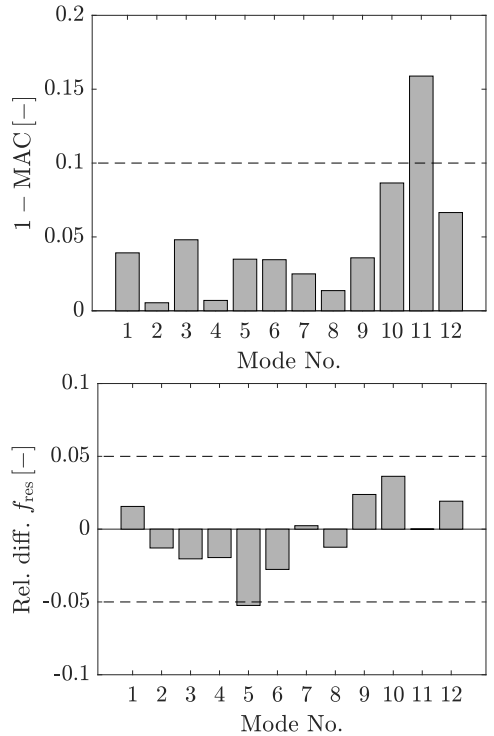

(b) plate 2

Figure 12: Relative differences of mode shapes (measured as 1-MAC) and natural frequencies between the identified and computed modes of two plates. 


\section{Boundary conditions for the floor model}

An overall FE model of the floor is generated by assembling the calibrated FE models of the beams and plates, as shown in section 4.1. This section mainly investigates the boundary conditions of the floor, as these strongly affect the structural vibration and the sound radiation at low and medium frequencies. In section 4.2, a dynamic test was performed on the floor to identify the eigenmodes of the floor. Section 4.3 discusses the numerical investigation of the boundary conditions.

\subsection{FE model of the floor}

Figure 13 shows the FE model of the floor, which consists of an assembly of the seven beam models and two plate models that were calibrated in sections 3.1 and 3.2, respectively. The neutral plane of the two plates is $9 \mathrm{~mm}$ higher than the top surfaces of the beams; this offset is accounted for in the model. Furthermore, it is assumed that the plate is rigidly coupled to the beam at the screw locations, such that the plate and the beam are vibrating without any relative translation or rotation. To achieve such a plate-beam connection through a screw, an element of the plate that is closest to the screw location is first selected, and each translational DOF of the selected plate element is coupled to the closest one of the beam in the same direction. According to the element sizes and types for both the plates and beams that are previously introduced, twelve pairs of plate and beam DOFs (i.e., the three displacement components at each of the four nodes involved) are coupled at a screw location, and the coupling area is the same as the plate element area, i.e., $2.5 \mathrm{~cm} \times 2.5 \mathrm{~cm}$.

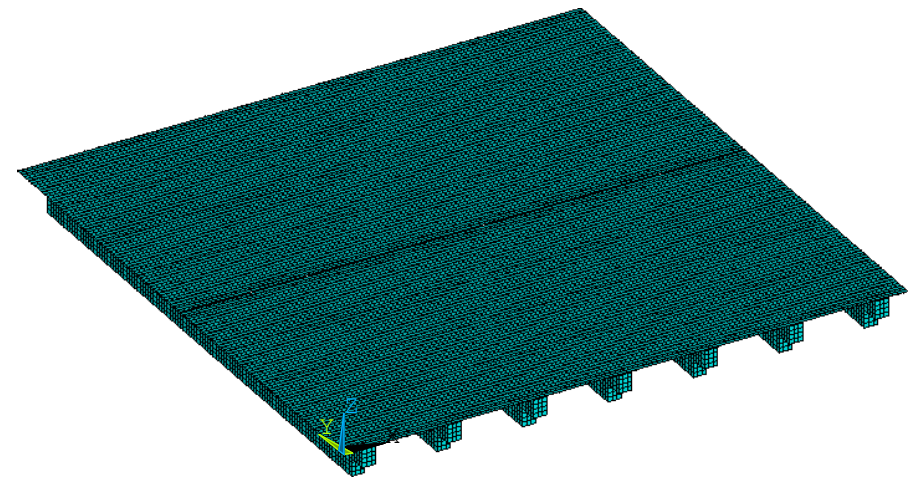

Figure 13: FE model of the floor in ANSYS.

As shown in the side view in figure 4, the floor is only supported by the opening stage at the beam ends, along the beam-opening contact surfaces in the $x y$-plane. Therefore, the boundary conditions were initially specified by restraining the translational DOFs in the $z$-direction at the bottom of all beam ends. The out-of-plane bending modes of the floor with natural frequencies below $150 \mathrm{~Hz}$ were computed. Figure 14 displays the mode shapes and natural frequencies of the first six computed modes. Note that the mode shapes are asymmetric in the $x$-direction, which is due to the variability of the beam properties.

\subsection{Modal identification of the floor}

A dynamic test was performed on the floor to determine its bending modes. This test was performed in seven setups. In each setup, $19 \mathrm{PCB}$ accelerometers with nominal sensitivities of 
$0.10 \mathrm{~V} /\left(\mathrm{m} / \mathrm{s}^{2}\right)$ and four Dytran accelerometers with nominal sensitivities of $0.01 \mathrm{~V} /\left(\mathrm{m} / \mathrm{s}^{2}\right)$ were attached to the floor. A hammer of the type Kistler 9726A20000 was applied to impact the floor at eight specific locations to ensure that most of the low-frequency out-of-plane bending modes were excited. The force and acceleration signals were acquired by the same NI PXI system described in section 3.1, and a sampling frequency of $1000 \mathrm{~Hz}$ was used. A modal analysis was performed using the input force data at eight impact locations and the output acceleration data at a total of 135 accelerometer locations. The procedure of the modal analysis is the same as the one described in section 3.2 .

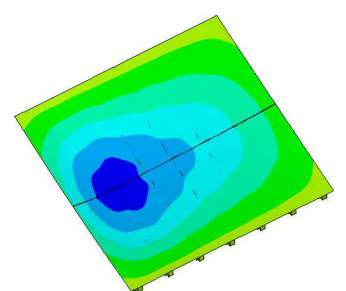

(a) mode 1, $47.42 \mathrm{~Hz}$

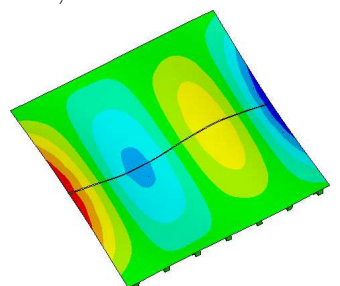

(d) mode $4,51.99 \mathrm{~Hz}$

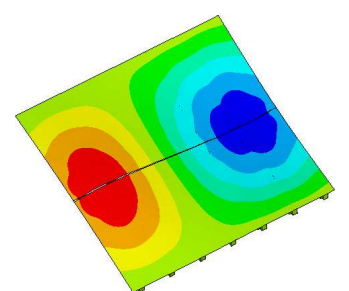

(b) mode 2, $47.93 \mathrm{~Hz}$

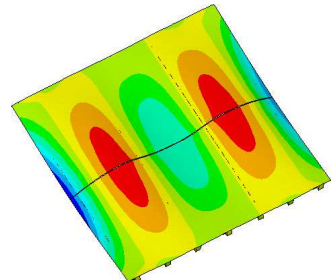

(e) mode $5,55.16 \mathrm{~Hz}$

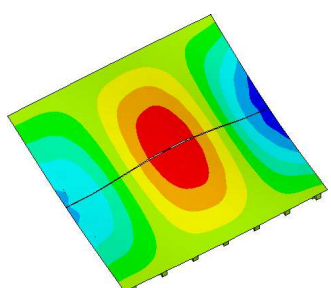

(c) mode $3,49.78 \mathrm{~Hz}$

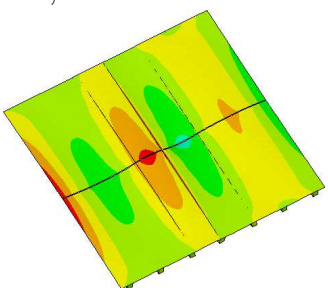

(f) mode $6,57.93 \mathrm{~Hz}$

Figure 14: Mode shapes and natural frequencies of the first six out-of-plane bending modes computed using the floor model with the initial boundary conditions.

Figure 15 shows the mode shapes and natural frequencies of six identified modes of the floor. The irregularities of the identified mode shapes indicate additional uncertainties in the assembled floor and the boundary conditions. A rather poor agreement was obtained between the identified mode shapes and computed ones in section 4.1, of which the MAC values are below 0.65. A possible reason is that the actual boundary conditions of the floor differ from the ones that were initially specified in the model.

\subsection{The boundary conditions}

The boundary conditions in the model of the floor were altered to investigate whether a better correspondence between the measured and computed modal characteristics could be achieved. Since the floor has a very low self weight, it is reasonable to suspect that some beam ends were slightly lifted from their support when screwing the plates onto the beams. Following this hypothesis, the boundary conditions of each beam end were modelled as either free or simply supported, and the resulting effect on the modal characteristics was investigated. Figure 16 displays the boundary conditions that leads to the best agreement with the mode shapes. Four beam ends are free, while for the other beam ends, the translational DOFs in the $z$-direction along the contact surfaces are restrained. Figure 17 displays the natural frequencies and mode shapes or the floor model after modifying the boundary conditions. Table 4 contains the MAC values and the relative differences of natural frequencies for the three measured and computed mode shapes that match 
relatively well. The MAC values are acceptable, while the first two frequency differences are above $10 \%$. The moderate correspondence can be attributed in part to the simplified, binary choice of boundary conditions, where the beam ends are either free or fully restrained in the vertical $(z)$ direction. Furthermore, in reality, the beam ends were also horizontally constrained due to friction along the beam-opening contact surface, which is disregarded in the floor model. Moreover, structural irregularities and uncertain imperfections also result in differences between the identified and computed modes. As these errors are difficult to reduce, the boundary conditions of figure 16 are adopted for the ongoing study.

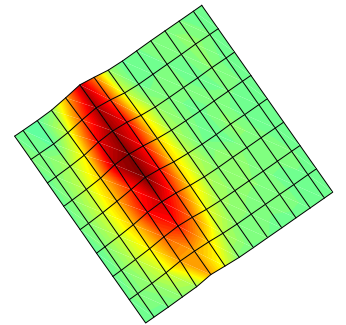

(a) mode $1,29.58 \mathrm{~Hz}$

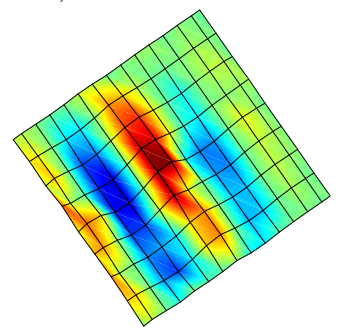

(d) mode $4,56.60 \mathrm{~Hz}$

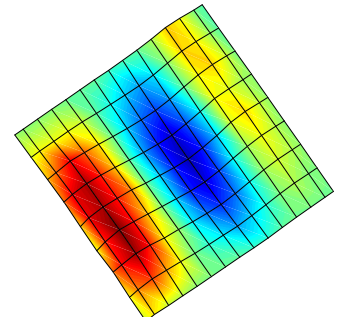

(b) mode $2,43.16 \mathrm{~Hz}$

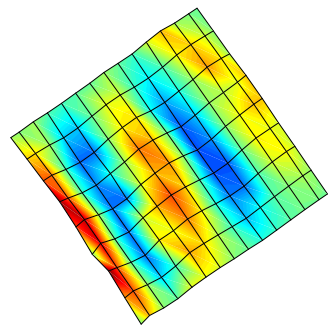

(e) mode $5,61.88 \mathrm{~Hz}$

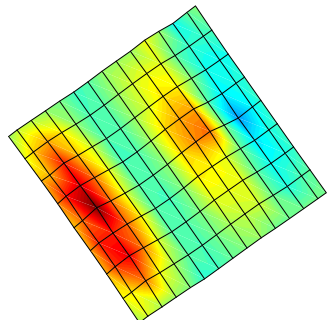

(c) mode $3,44.44 \mathrm{~Hz}$

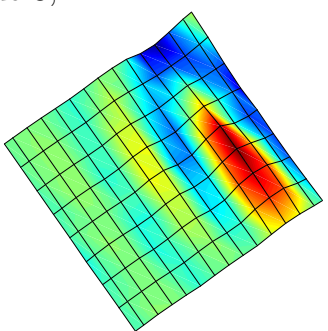

(f) mode $6,80.45 \mathrm{~Hz}$

Figure 15: Mode shapes and natural frequencies of six identified out-of-plane bending modes of the floor.

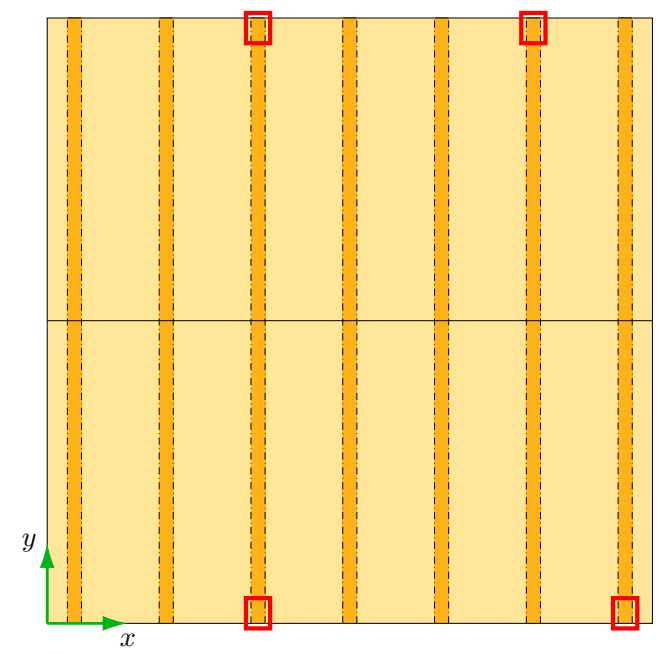

Figure 16: Plan of the floor with the improved boundary conditions for the floor model. Four beam ends (marked by red boxes) are free, while for the other beam ends, the translational DOFs in the $z$-direction along the contact surfaces are restrained. 


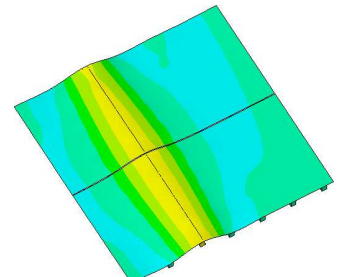

(a) mode 1, $25.13 \mathrm{~Hz}$

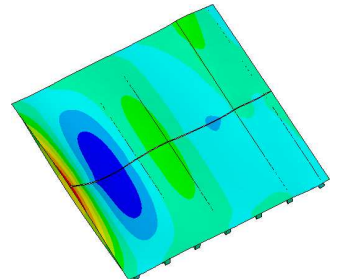

(d) mode 4, $58.21 \mathrm{~Hz}$

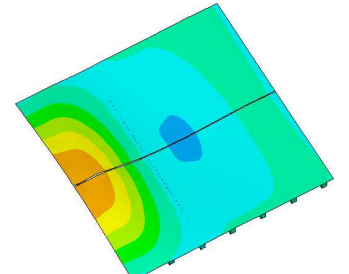

(b) mode $2,49.36 \mathrm{~Hz}$

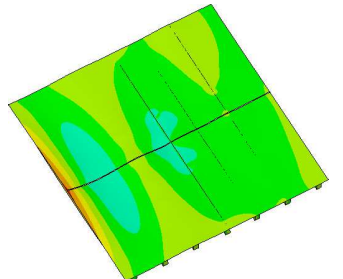

(e) mode $5,60.47 \mathrm{~Hz}$

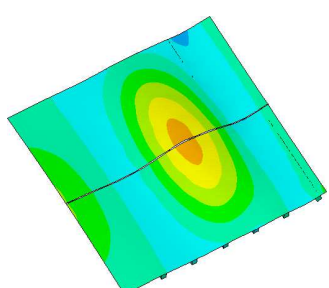

(c) mode $3,51.28 \mathrm{~Hz}$

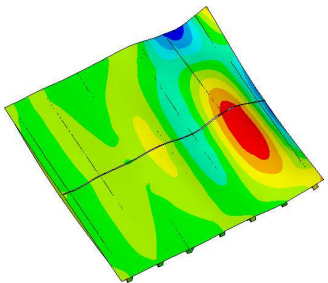

(f) mode $6,82.79 \mathrm{~Hz}$

Figure 17: Mode shapes and natural frequencies of six out-of-plane bending modes computed using the floor model with the modified boundary conditions.

\begin{tabular}{c|ccc}
\hline comp. mode No. & 1 & 2 & 6 \\
id. mode No. & 1 & 2 & 6 \\
\hline MAC value & 0.93 & 0.75 & 0.78 \\
Relative difference of $f_{\text {res }}[-]$ & -0.150 & 0.144 & 0.029 \\
\hline
\end{tabular}

Table 4: MAC values and relative differences of natural frequencies between the computed and identified mode 1,2 , and 6 .

\section{Impact sound prediction and experimental validation}

In this section, the computed impact sound radiation by the timber floor is discussed and experimentally validated. Section 5.1 describes the measurement setups of two impact sound radiation tests, an acoustic reverberation test, and a structural reverberation test. Sections 5.2 and 5.3 discuss the validation of the computed sound pressure levels for two types of excitation.

\subsection{Measurement setup}

Two impact sound radiation tests were performed for two sources of excitation: an instrumented hammer of the type Kistler 9726A20000 and the ISO tapping machine. The tapping machine impact test was performed in 16 setups. In eight setups, the tapping machine was placed above a beam, and in the other eight setups, it was placed at midspan between two beams. These locations are shown in figure 18, indicated as 'beam locations' and 'inter-beam locations', respectively. In the hammer impact test, the impact locations are located at the central points of the tapping machine locations in figure 18. This test allows acquiring the input hammer force. For all test setups, the sound pressure levels were measured at eight microphone locations in the central zone of the receiving room, using two microphones of the type Brüel \& Kjaer 4188 and preamplifiers of the type Brüel \& Kjaer 2671.

The acoustic damping used in Eq. (23) was estimated by an acoustic reverberation test. The receiving room was acoustically excited eight times by a loudspeaker, and the resulting sound 
pressure level after each excitation was acquired by a microphone at a location in the central zone of the room. The acoustic reverberation time $T_{\mathrm{a}}$, corresponding to the decay of the sound pressure level by $60 \mathrm{~dB}$ after each acoustic excitation, was evaluated using the interrupted noise method as standardized in ISO-3382 [41]. The acoustic damping loss factor $\eta_{\mathrm{a}}$ at an angular frequency $\omega$ was computed using Eq. (24).

(a)

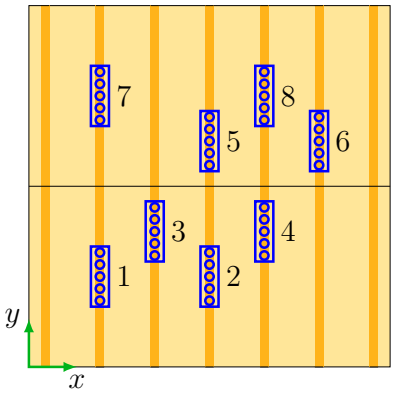

(b)

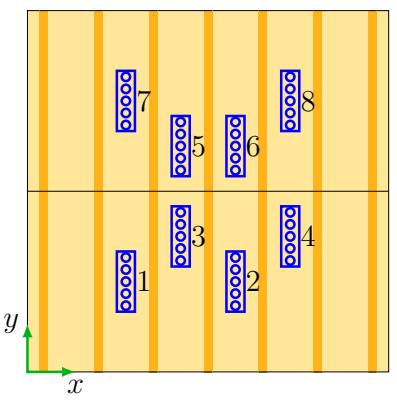

Figure 18: Measurement setup of the ISO tapping machine impact test: (a) eight beam locations and (b) eight inter-beam locations. The central hammer location of each tapping machine location coincides with an excitation location in the hammer impact test.

Analogously, the structural damping used in the computation was estimated by a structural reverberation test. Single impulse excitations were given by a hammer at 20 locations in the central part of the floor, and the resulting acceleration was acquired by accelerometers at 23 locations. The structural reverberation time $T_{\mathrm{s}}$, corresponding to the decay of the acceleration level by $60 \mathrm{~dB}$ after each impulse excitation, was evaluated using the integrated impulse response method as standardized in ISO-3382 [41]. Next, the structure damping loss factor $\eta_{\mathrm{s}}$ at angular frequency $\omega$ was computed as follows:

$$
\eta_{\mathrm{s}}=\frac{6 \ln (10)}{\omega T_{\mathrm{s}}}
$$

Figure 19 displays the measured reverberation time of the receiving room and the damping loss factor of the floor. The room reverberation time was averaged over eight microphone locations, while the structural damping loss factor was averaged over both the impact and accelerometer locations.

\subsection{Validation for hammer excitation}

Figure 20 displays the PSDs of the measured impact force for the excitation on eight beam locations and eight inter-beam locations in the hammer excitation test. The impact forces applied at different impact locations were of the same magnitude. The results in figure 20 are then applied to compute the floor vibration and resulting sound field. Figure 21 shows the measured $1 / 48-$ and $1 / 3$-octave band integrated normalized sound pressure levels that are spatially averaged in the receiving room, and the ones computed using the diffuse field model. The results are averaged over hammer excitations at the eight beam locations and the eight inter-beam locations shown in figure 18, with the single-sided PSDs of the impact force shown in figure 20. Additional spectra are shown at frequencies up to $315 \mathrm{~Hz}$, which are deterministically computed using a $\mathrm{FE}$ room model [43]. 

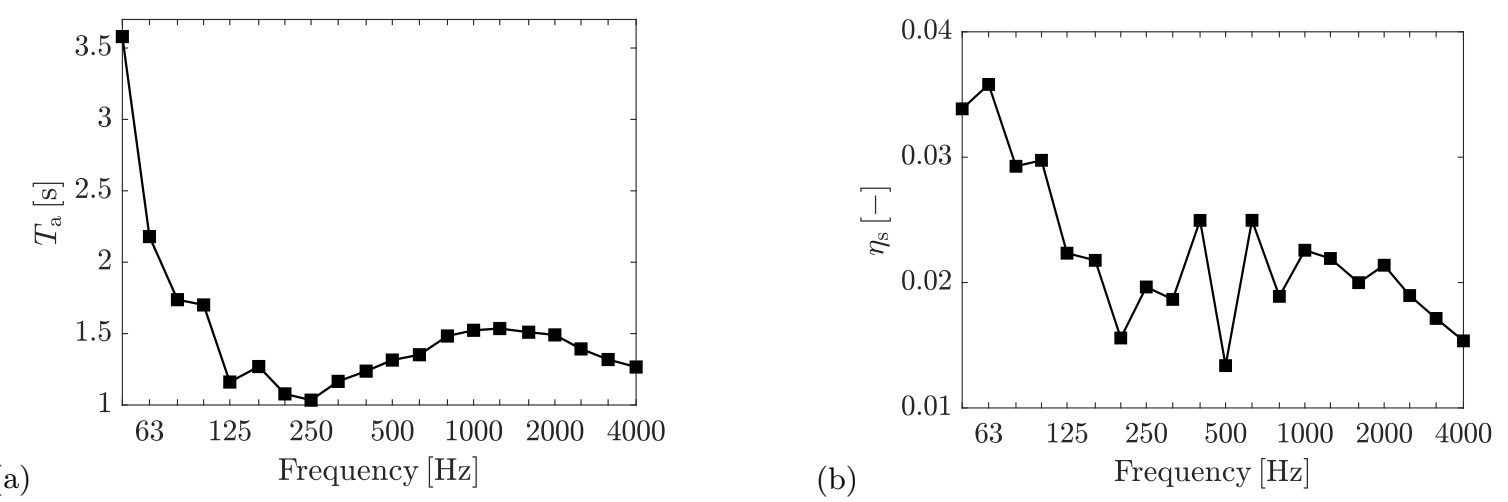

Figure 19: (a) Reverberation time of the receiving room estimated by the acoustic reverberation test. (b) Damping loss factor of the floor estimated by the structural reverberation time test.

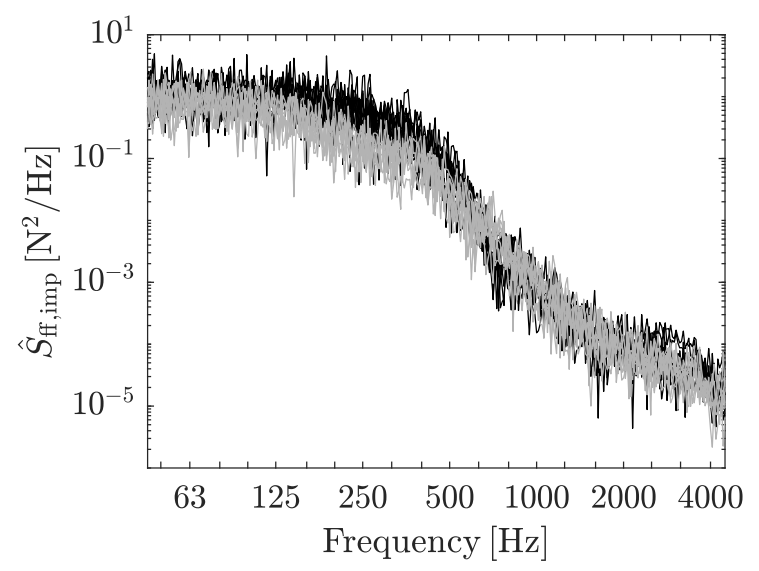

Figure 20: Measured single-sided PSDs of the impact force spectra for excitation on eight beam locations (black solid line) and eight inter-beam locations (gray solid line) in the hammer excitation test. Each curve is averaged over the microphone setups.

In general, the measurement results agree relatively well with the ones computed by the diffuse field model. Discrepancies between the measured and computed 1/48-octave band integrated results are attributed to inaccuracies of the FE floor model, in particular with respect to the boundary conditions, and to measurement errors. At the lowest frequency bands, the sound pressure levels predicted using the diffuse field model are largely overestimated. This may be attributed to the fact that the room sound field is modeled as diffuse, i.e., interaction between the floor and room modes are not accounted for. For the two identified modes 4 and 5 in figure 15, the wavelength in the $y$-direction is twice the corresponding floor dimension. This is the same for the acoustic modes in the same direction, resulting in cancellation of the acoustic modes [23, 24]. The influence of the floor-room mode interaction is easily checked using the FE model, in which the room modes are modeled. At frequencies between $125 \mathrm{~Hz}$ and $315 \mathrm{~Hz}$, the result of the two room models are very close, and the diffuse field model is computationally more efficient. From $315 \mathrm{~Hz}$ onwards, due to the large computational cost, the sound pressure levels are not computed using the FE room model. 

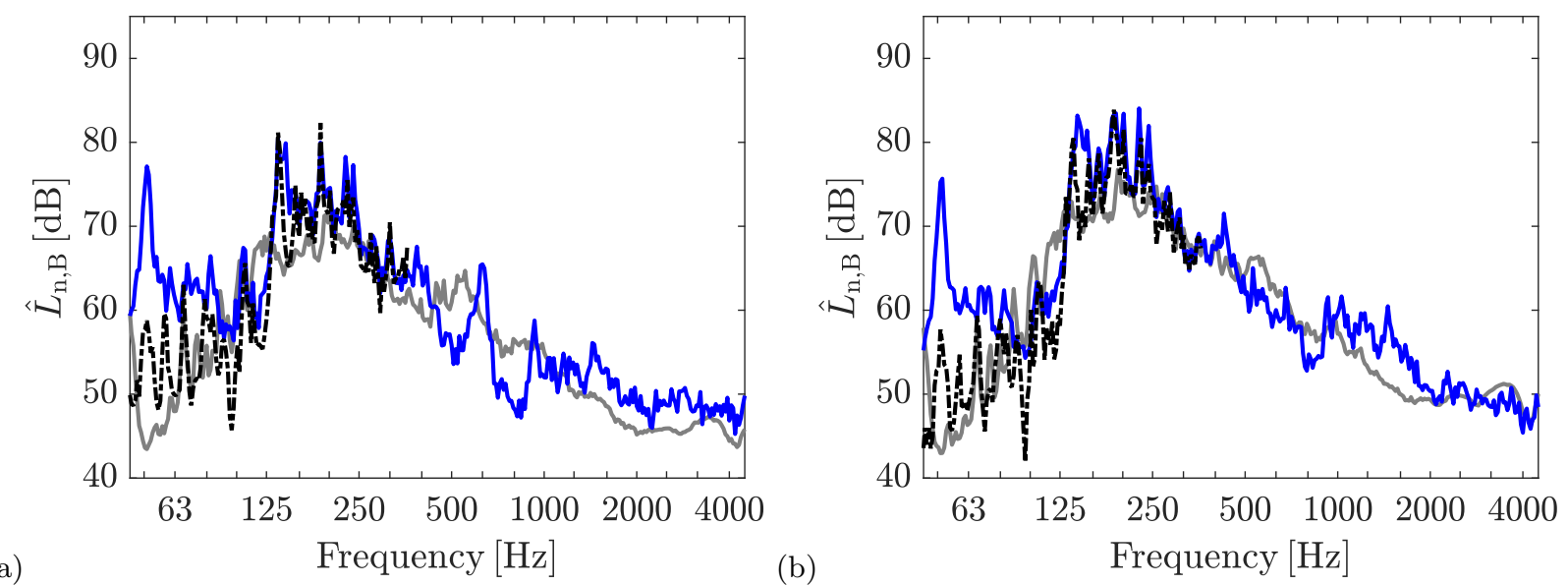

(a)

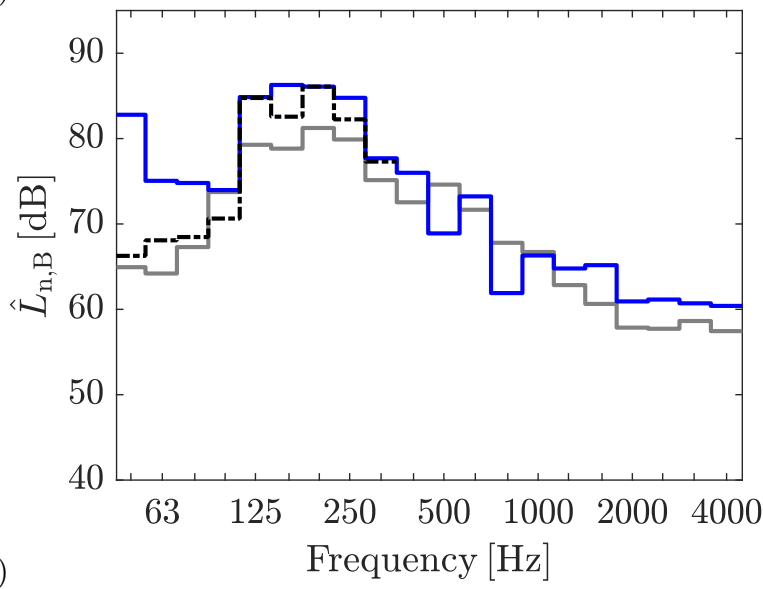

(b)

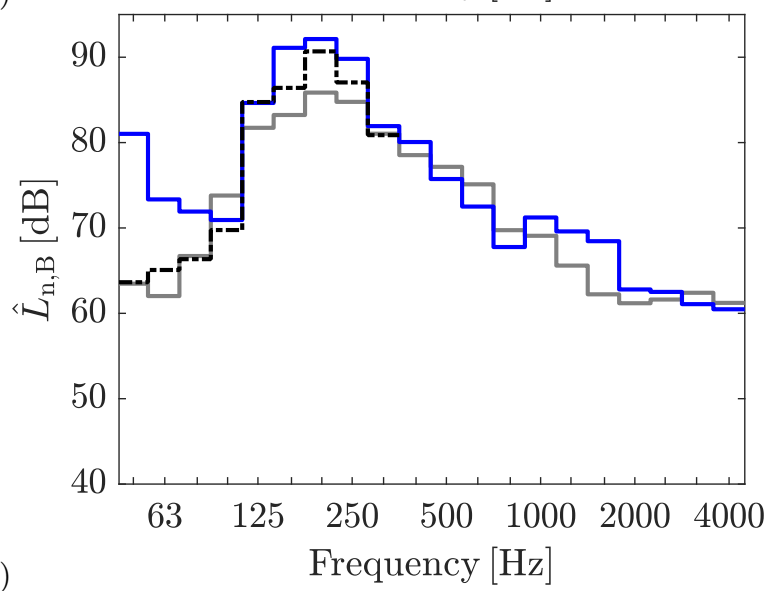

Figure 21: Measured (solid gray lines) (a,b) 1/48- and (c,d) 1/3-octave band integrated normalized sound pressure levels that are spatially averaged in the receiving room underneath the timber joist floor, and the ones computed using the diffuse field model (solid blue lines) and a FE room model (dash-dotted black lines) at frequencies up to $315 \mathrm{~Hz}$. The results are averaged over the hammer excitations at (a,c) eight beam locations and (b,d) eight inter-beam locations of the floor, with the single-sided PSDs of the impact force spectra shown in figure 20.

\subsection{Validation for tapping machine excitation}

The ISO tapping machine impact force is computed using the approach in section 2.1. To compute the local impedance, Eq. (6) was applied using the effective isotropic properties for the orthotropic plates:

$$
E=E_{\mathrm{z}}, \quad \nu=\sqrt{\nu_{\mathrm{xz}} \nu_{\mathrm{yz}}}
$$

The global driving point impedance at frequencies up to $4500 \mathrm{~Hz}$ is computed using modal summation, in which the mode shapes and natural frequencies are computed by the FE model described in section 4. At frequencies above $4500 \mathrm{~Hz}$, the local impedance is assumed to be much lower than the global impedance, so $Z_{\mathrm{dp}} \approx Z_{\mathrm{L}}$. The integral $I_{0}$ in Eq. (10) is first computed using a frequency resolution $\Delta f=1 \mathrm{~Hz}$ and a Nyquist frequency $f_{\mathrm{Nyq}}=10^{5} \mathrm{~Hz}$. For the 16 tapping machine setups shown in figure $18, I_{0}$ is close to $1 \mathrm{~kg}^{-1}$ for all the hammer locations. Next, to numerically compute 
the impact force spectra, a time resolution $\Delta t=5 \times 10^{-6} \mathrm{~s}$, a frequency resolution $\Delta f=1 \mathrm{~Hz}$, an upper time limit $T=1 \mathrm{~s}$, and a Nyquist frequency $f_{\mathrm{Nyq}}=10^{5} \mathrm{~Hz}$ are adopted.

Figure 22 shows the computed Fourier series coefficient magnitudes of the impact force corresponding to the excitations at the 40 hammer locations above beams and the 40 hammer locations between beams, and the corresponding single-sided PSDs computed using Eq. (16). In figure 22a, each spectrum is controlled by the driving point impedance at frequencies well below the corresponding cut-off frequency $f_{\text {cut }}=1 /\left(2 t_{\text {cut }}\right)$, which varies between $140 \mathrm{~Hz}$ and $500 \mathrm{~Hz}$ in this study.

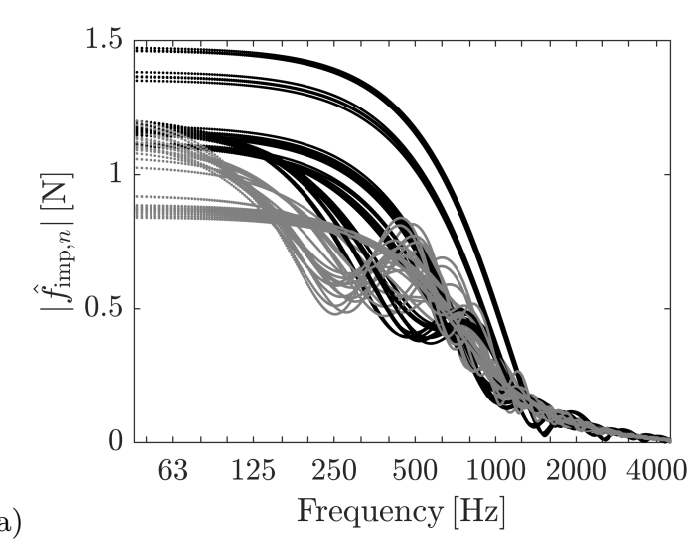

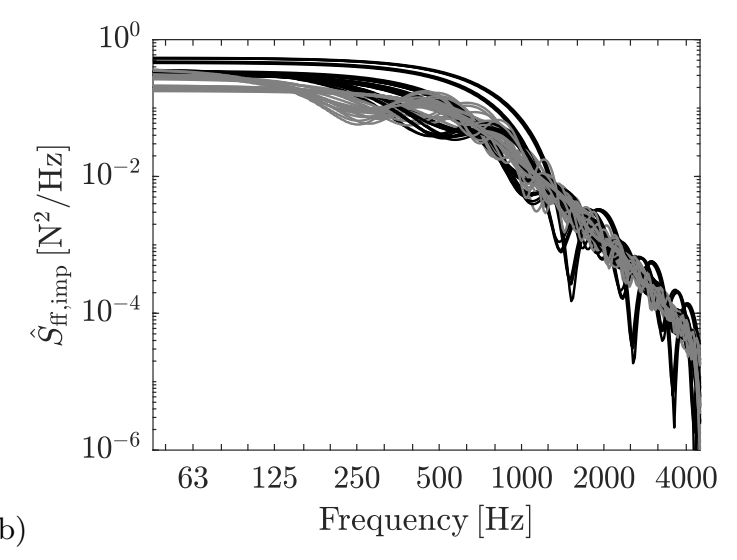

Figure 22: Computed (a) Fourier series coefficient magnitudes of the impact force and (b) single sided PSDs of the squared impact force corresponding to excitations at the 40 hammer locations above beams ((a) black dots, (b) black lines) and at the 40 hammer locations between beams ((a) gray dots, (b) gray lines) in the tapping machine excitation test.

Since at low frequencies there are clear differences in the Fourier series coefficient magnitudes $\left|\hat{f}_{\mathrm{imp}, n}\right|$, the sensitivity of the impact location on the tapping machine impact force is further investigated. Figure 23 shows the Fourier series coefficient magnitudes $\left|\hat{f}_{\text {imp }, n}\right|$ of the impact force at $f_{n}=50 \mathrm{~Hz}$ for all possible hammer locations on the floor. For the impact locations above beams, the Fourier series coefficient magnitudes are the highest at the screw locations, and are generally around $1.1 \mathrm{~N}$ between the screws, which agrees with the force variation at $f_{n}=50 \mathrm{~Hz}$ in figure $22 \mathrm{a}$. For the impact locations between beams, the Fourier series coefficient magnitudes vary from $0.8 \mathrm{~N}$ to $1.2 \mathrm{~N}$, depending on the vicinity of a screw location. A slight shift the impact location along the beam direction can have a large influence on the impact force. This explains the difference between the low frequency spectra in figure 22a for the different inter-beam impact locations.

Figure 24 shows the measured 1/48- and 1/3-octave band integrated normalized sound pressure levels that are spatially averaged in the receiving room underneath the timber joist floor, and compares these to the ones computed using the diffuse field model, and using the FE room model at frequencies up to $315 \mathrm{~Hz}$. The results are averaged over the tapping machine excitations at beam and inter-beam locations. The computed results are obtained using the computed PSDs of the squared tapping machine impact force given in figure 22.

As similar as observed in figure 21, the prediction results of the diffuse field model at the lowest frequency bands differ from the ones of the FE room model, indicating again that the interaction between the floor and room modes are important. At medium frequency bands, the agreement between the measurement and prediction is generally less satisfactory than the one in figure 21, indicating some errors lying in the computed tapping machine impact force.

The correspondence between the measured $1 / 3$-octave band integrated results in figure $24 \mathrm{c}$ and 


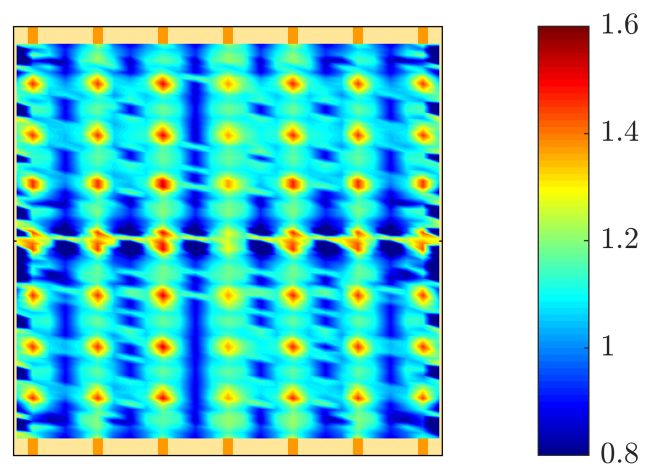

Figure 23: Fourier series coefficient magnitudes $\left|\hat{f}_{\mathrm{imp}, n}\right|$ (in $[\mathrm{N}]$ ) of the tapping machine impact force at $f_{n}=50 \mathrm{~Hz}$ corresponding to all possible tapping hammer locations on the floor.
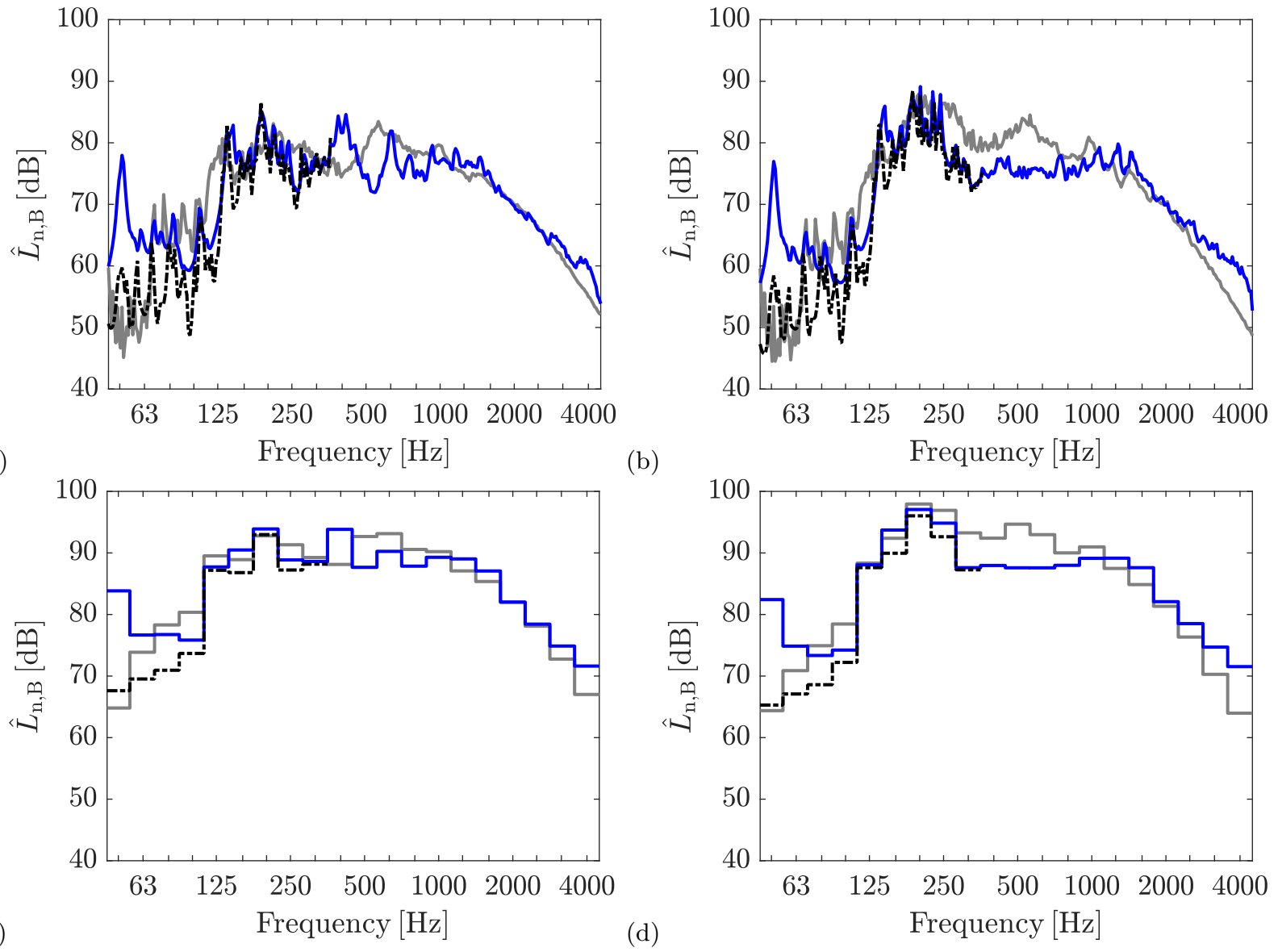

Figure 24: Measured (solid gray lines) (a,b) 1/48- and (c,d) 1/3-octave band integrated normalized sound pressure levels that are spatially averaged in the receiving room underneath the timber joist floor, and the ones computed using the diffuse field model (solid blue lines) and a FE room model (dash-dotted black lines) at frequencies up to $315 \mathrm{~Hz}$. The results are averaged over hammer excitations at (a,c) 40 beam locations and (b,d) 40 inter-beam locations of the floor. The computed results are obtained using the computed PSDs of the squared tapping machine impact force given in figure 22 . 
$\mathrm{d}$ and the ones computed using the diffuse field model is further evaluated using single number ratings in accordance with ISO-717-2-1996 [42]. Table 5 shows the single number rating values in the form of $\hat{L}_{\mathrm{n}, \mathrm{w}}\left(C_{\mathrm{I}}\right)$ for the computed and measured results with the beam and inter-beam excitations, and their difference of $\hat{L}_{\mathrm{n}, \mathrm{w}}$ and the term $\hat{L}_{\mathrm{n}, \mathrm{w}}+C_{\mathrm{I}}$, respectively. Since the spectra are rated at frequencies between $100 \mathrm{~Hz}$ and $3150 \mathrm{~Hz}$, the results are not influenced by the large discrepancies at frequencies below $100 \mathrm{~Hz}$. For both the beam and inter-beam excitation, the computed single number rating differs only $0-2 \mathrm{~dB}$ from the measured one, which again indicates satisfactory correspondence between the measured and computed sound pressure levels at the considered frequency range. Therefore, the numerical model given in section 2 can be considered suitable for the prediction of sound radiation induced by the ISO tapping machine in this case study.

\begin{tabular}{c|cc}
\hline & Beam excitations & Inter-beam excitations \\
\hline$\hat{L}_{\mathrm{n}, \mathrm{w}, \mathrm{c}}\left(C_{\mathrm{I}, \mathrm{c}}\right)[\mathrm{dB}]$ & $90(-4)$ & $91(-4)$ \\
$\hat{L}_{\mathrm{n}, \mathrm{w}, \mathrm{m}}\left(C_{\mathrm{I}, \mathrm{m}}\right)[\mathrm{dB}]$ & $90(-4)$ & $91(-2)$ \\
$\hat{L}_{\mathrm{n}, \mathrm{w}, \mathrm{c}}-\hat{L}_{\mathrm{n}, \mathrm{w}, \mathrm{m}}[\mathrm{dB}]$ & 0 & 0 \\
$\hat{L}_{\mathrm{n}, \mathrm{w}, \mathrm{c}}+C_{\mathrm{I}, \mathrm{c}}-\left(\hat{L}_{\mathrm{n}, \mathrm{w}, \mathrm{m}}+C_{\mathrm{I}, \mathrm{m}}\right)[\mathrm{dB}]$ & 0 & -2 \\
\hline
\end{tabular}

Table 5: Single number rating $\hat{L}_{\mathrm{n}, \mathrm{w}}\left(C_{\mathrm{I}}\right)$ between the diffuse field model computed (indicated by the subscript 'c') and measured (indicated by the subscript ' $\mathrm{m}$ ') normalized sound pressure levels shown in figure $24 \mathrm{c}$ and d, and their difference of $\hat{L}_{\mathrm{n}, \mathrm{w}}$ and the term $\hat{L}_{\mathrm{n}, \mathrm{w}}+C_{\mathrm{I}}$.

\section{Conclusion}

In this work, a state-of-the-art numerical method was discussed, which allows predicting the impact sound radiation by finite timber joist floors with complex configurations. The prediction method accounts for the influence on the impact force of both the local floor deformation at the contact interface with the impacting mass, and the global floor vibration. The global floor vibration is modeled in detail using the finite element method. The radiated sound field is taken to be diffuse with weak coupling towards the floor, such that the radiated sound power equals the power that is radiated into the diffuse field.

The performance of the method was thoroughly investigated considering a bare timber joist floor. The natural frequencies of the decoupled floor components (joists and plywood plates) were identified by modal testing and compared to the predictions by the corresponding finite element model parts. It was found that orthotropic material models are needed for a high prediction accuracy, both for the plates and the joists. Furthermore, substantial variation of the material properties was discovered, both for the joists and the plywood plates.

The accuracy of the floor assembly model was subsequently investigated, also by means of modal testing. Substantial deviations were observed between the measured modes and the computed ones. They could be attributed to a large part to a mismatch in boundary conditions; a better match was obtained when four of the fourteen beam ends were taken to be unsupported. Most probably, the screwing of the plates onto the beams resulted in the lifting of some beam ends from their supports.

Finally, the radiated sound pressure levels were measured and computed, both for impact hammer and tapping machine excitation, and both for excitation locations on top of the beams, and 
on the bays in between. Although differences were observed for beam and inter-beam excitation at certain frequencies, they were relatively small in general. A satisfactory agreement between measurements and computations was observed. At very low frequencies, the interaction between the floor and room modes can play an important role, and a good agreement was obtained by adopting a modal room model. When rating the computed and measured normalized sound pressure levels according to ISO 717-2-1996, their discrepancies at frequencies below $100 \mathrm{~Hz}$, on the other hand, are not taken into account. Differences in the single number ratings did not exceed $2 \mathrm{~dB}$, indicating again good correspondence between measurements and computations in this case study.

\section{Acknowledgments}

This research was funded by the European Research Council (ERC) Executive Agency, in the form of an ERC Starting Grant under the Horizon 2020 framework program, project 714591 VirBAcous, and by the KU Leuven Dept. of Civil Engineering. The financial support from the European Commission and from KU Leuven is gratefully acknowledged. The authors would also like to thank Jan Van den Wyngaert for his help with the impact sound radiation measurement, and Bernd Salaets, Jimmy Van Criekingen, and Willy Bruyninckx for their contribution in the installation of the timber joist floor.

\section{References}

[1] J. Negreira, A. Sjöström, and D. Bard. Low frequency vibroacoustic investigation of wooden T-junctions. Applied Acoustics, 105:1-12, 2016.

[2] M. Kohrmann. Numerical methods for the vibro-acoustic assessment of timber floor constructions. PhD thesis, Technical University Munich, 2017.

[3] J. Negreira. Vibrations in lightweight buildings - perception and prediction. PhD thesis, Lund University, 2013.

[4] B. Ingelaere. COST Action: Net-acoustics for timber based lightweight buildings and elements - Chapter 4: acoustic design of lightweight timber frame constructions. Technical Report FP0702, BBRI, Brussels, 2012.

[5] A. Homb, C. Guigou-Carter, K. Hagberg, and H. Schmid. Impact sound insulation of wooden joist constructions: collection of laboratory measurements and trend analysis. Building Acoustics, 23(2):73-91, 2016.

[6] A. Homb, C. Guigou-Carter, K. Hagberg, M. Spöh, and H. Ferk. Validation of prediction tools and constructions - grouping, verification measurements and trend analysis. Report 57, RISE Research Institutes of Sweden AB, 2017.

[7] International Organization for Standardization. ISO 10140-5: Acoustics - Laboratory measurement of sound insulation of building elements - Part 5: Requirements for test facilities and equipment, 2010.

[8] M. Heckl. Körperschallübertragung bei homogenen platten beliebiger dicke. Acta Acustica united with Acustica, 49(3):183-191, 1981.

[9] S. Ljunggren. A new type of solution for plate vibrations at low frequencies. Journal of Sound and Vibration, 116(1):125-136, 1987.

[10] S.P. Timoshenko and J.N. Goodier. Theory of elasticity. McGraw-Hill, New York, NY, 3rd edition, 1970.

[11] B.A.T. Petersson and M. Heckl. Concentrated excitation of structures. Journal of Sound and Vibration, 196(3):195-321, 1996.

[12] J. Brunskog and P. Hammer. Rigid indenter excitation of plates. Acta Acustica united with Acustica, 89(3):460470, 2003.

[13] J. Brunskog and P. Hammer. The interaction between the ISO tapping machine and lightweight floors. Acta Acustica united with Acustica, 89(2):296-308, 2003.

[14] A. Rabold, M. Buchschmid, A. Düster, G. Müller, and E. Rank. Modelling the excitation force of a standard tapping machine on lightweight floor structures. Building Acoustics, 17(3):175-197, 2010.

[15] V. Wittstock. On the spectral shape of the sound generated by standard tapping machines. Acta Acustica united with Acustica, 98:301-308, 2012.

[16] J. Brunskog and P. Hammer. Prediction model for the impact sound level of lightweight floors. Acta Acustica united with Acustica, 89(2):309-322, 2003. 
[17] H. Chung and G. Emms. Fourier series solutions to the vibration of rectangular lightweight floor/ceiling structures. Acta Acustica united with Acustica, 94(3):401-409, 2008.

[18] K.A. Dickow, J. Brunskog, and M. Ohlrich. Modal density and modal distribution of bending wave vibration fields in ribbed plates. Journal of the Acoustical Society of America, 134(4):2719-2729, 2013.

[19] A.R. Mayr and B.M. Gibbs. Point and transfer mobility of point-connected ribbed plates. Journal of Sound and Vibration, 330:4798-4812, 2011.

[20] A.R. Mayr and B.M. Gibbs. Approximate method for obtaining source quantities for calculation of structureborne sound transmission into lightweight buildings. Applied Acoustics, 110:81-90, 2016.

[21] A. Paolini, S. Kollmannsberger, C. Winter, M. Buchschmid, G. Müller, A. Rabold, S. Mecking, U. Schanda, and E. Rank. A high-order finite element model for vibration analysis of cross-laminated timber assemblies. Building Acoustics, 24(3):135-158, 2017.

[22] D. Bard, J. Negreira, C. Guigou-Carter, G. Borello, J. Kouyoumji, A. Speranza, C. Coguenanff, and K. Hagberg. Modelling prerequisites - FEM/SEA impact and airborne sound. Report 56, RISE Research Institutes of Sweden $\mathrm{AB}, 2017$.

[23] A. Neves e Sousa and B.M. Gibbs. Low frequency impact sound transmission in dwellings through homogeneous concrete floors and floating floors. Applied Acoustics, 72(4):177-189, 2011.

[24] A. Neves e Sousa and B.M. Gibbs. Parameters influencing low frequency impact sound transmission in dwellings. Applied Acoustics, 78:77-88, 2014.

[25] C. Hopkins. Sound insulation. Elsevier Ltd., Oxford, 2007.

[26] L. Cremer, M. Heckl, and B.A.T. Petersson. Structure-borne sound: Structural vibrations and sound radiation at audio frequencies. Springer, Berlin, 3rd edition, 2005.

[27] R.S. Langley. Numerical evaluation of the acoustic radiation from planar structures with general baffle conditions using wavelets. Journal of the Acoustical Society of America, 121(2):766-777, 2007.

[28] I.L. Vér. Impact noise isolation of composite floors. Journal of the Acoustical Society of America, 50(4):10431050, 1971.

[29] E.G. Williams and G.D. Maynard. Numerical evaluation of the Rayleigh integral for planar radiators using the FFT. Journal of the Acoustical Society of America, 72(6):2020-2030, 1982.

[30] R.S. Langley and V. Cotoni. Response variance prediction for uncertain vibro-acoustic systems using a hybrid deterministic-statistical method. Journal of the Acoustical Society of America, 122(6):3445-3463, 2007.

[31] C. Decraene, A. Dijckmans, and E.P.B. Reynders. Fast mean and variance computation of the diffuse sound transmission through finite-sized thick and layered wall and floor systems. Journal of Sound and Vibration, 422:131-145, 2018.

[32] R.S. Langley and J.A. Cordioli. Hybrid deterministic-statistic analysis of vibro-acoustic systems with domain couplings on statistical components. Journal of Sound and Vibration, 321(3-5):893-912, 2009.

[33] T.E. Vigran. Building Acoustics. Taylor \& Francis, Oxon, UK, 2008.

[34] E. Reynders. System identification methods for (operational) modal analysis: review and comparison. Archives of Computational Methods in Engineering, 19(1):51-124, 2012.

[35] E. Reynders, C. Van hoorickx, and A. Dijckmans. Sound transmission through finite rib-stiffened and orthotropic plates. Acta Acustica united with Acustica, 102(6):999-1010, 2016.

[36] E. Reynders, M. Schevenels, and G. De Roeck. MACEC: A Matlab toolbox for experimental and operational analysis. Report BWM-2008-07, Department of Civil Engineering, KU Leuven, April 2008.

[37] E. Reynders and G. De Roeck. Reference-based combined deterministic-stochastic subspace identification for experimental and operational modal analysis. Mechanical Systems and Signal Processing, 22(3):617-637, 2008.

[38] R. Ross. Wood handbook: wood as an engineering material. Technical Report 190, USDA Forest Service, Forest Products Laboratory, 2010.

[39] M. Huber. The theory of crosswise reinforced ferroconcrete slabs and its application to various important constructional problems involving rectangular slabs. Der Bauingenieur, 4(12):354-360, 1923.

[40] R.J. Allemang and D.L. Brown. A correlation coefficient for modal vector analysis. In Proceedings of the 1st International Modal Analysis Conference, pages 110-116, Orlando, FL, 1982.

[41] International Organization for Standardization. ISO 3382:1997: Acoustics - Measurement of the reverberation time of rooms with reference to other acoustical parameters, 1997.

[42] International Organization for Standardization. ISO 717-2: Acoustics - Rating of sound insulation in buildings and of building elements - Part 2: Impact sound insulation, 1996.

[43] N. Atalla and F. Sgard. Finite element and boundary methods in structural acoustics and vibration. Taylor \& Francis, Boca Raton, FL, 2015. 